\title{
ESTUDIO MÉTRICO DEL ENDECASÍLABO EN LOS SONETOS DE DIEGO HURTADO DE MENDOZA
}

\author{
SANDRa Pesqueira Rodríguez \\ Universidad de Vigo
}

\section{INTRODUCCIÓN}

Con probabilidad, Diego Hurtado de Mendoza es más conocido por sus composiciones en octosílabos que por ser uno de los precursores en el uso del soneto en España; sin embargo, nos ha parecido interesante tratar de reconstruir, en este estudio, los pasos que marcaron el tránsito de este poeta formado en el arte del cancionero hasta el mundo del metro italiano. En cualquier caso, se tiene constancia de que Mendoza empleó el octosílabo y el endecasílabo de manera indistinta a lo largo de su dilatada trayectoria poética, y que con sus primeros ensayos sonetiles contribuyó a la aclimatación de nueva estrofa en la literatura española; si bien no siempre innovación y calidad han corrido la misma suerte.

Diego Hurtado de Mendoza está vinculado por una serie de rasgos comunes y coincidencias vitales a los poetas que forman la llamada «Primera 
generación petrarquista». ${ }^{1}$ Muchos eran los aspectos que lo aproximaban a la generación de Garcilaso, Acuña, Cetina...: edad, aficiones, formación en la cultura clásica grecolatina, su condición de ser «hijos no primogénitos» en familias nobles. ${ }^{2}$ Hecho, este último, que los llevó a vincular su vida al ejercito y al servicio del Rey.

Su condición de militares les lleva a Italia donde encontrarán una experiencia vital que les marcará su vida y su formación poética. Allí conocen, y conviven en algún caso, con los poetas italianos más importantes: Petrarca, Dante, Tasso, Ariosto... ${ }^{3}$ De ellos recogerán el uso del soneto y la adopción del verso endecasílabo. Pero es de suponer que para esta generación de poetas, educados y formados en la escuela tradicional cancioneril, esa evolución hacia el mundo de los sonetos requería de un proceso complicado de asimilación y adaptación a una nueva forma de hacer poesía que tenía su origen en Italia.

Por ello, la intención en este estudio es la de analizar ese proceso de adaptación al metro italiano de un poeta que comienza su carrera poética en la poesía de cancionero y el uso del octosílabo. A través de un análisis métrico descriptivo de los treinta y tres sonetos de Diego Hurtado de Mendoza intentaré averiguar cuales fueron los signos de inadaptación, si es que existieron, al arte nuevo en este poeta; si su antigua formación métrica favoreció que surgieran errores en el uso del endecasílabo o, si por el contrario, Mendoza logró adaptarse perfectamente al límite del verso sin dar lugar a versos hipermétricos o a dudosas licencias métricas. A la vez, trataremos de comprobar si para Mendoza el endecasílabo fue un juego con el que poder experimentar e innovar; si consiguió dejar atrás, como ya lo había hecho antes Garcilaso, el uso del verso agudo que tanto convenía para la viveza del octosílabo pero que su utilización en el endecasílabo podría ser considerada

\footnotetext{
${ }^{1}$ A. Gallego Morell, «Escuela de Garcilaso» en Renacimiento español, Universidad de Granada, Comares S. L., 2003. p. 243; y A. Zamora Vicente, Sobre petrarquismo, Santiago de Compostela, Universidad de Santiago 1948.

${ }^{2}$ He utilizado como libro de referencia sobre la biografía de Diego Hurtado de Mendoza: la edición D. Hurtado de Mendoza, Poesías, ed. de Luis Díaz Larios y Olga Gete Carpio, Madrid, Cátedra, 1990. No obstante, también he tenido en cuenta la edición: D. Hurtado de Mendoza, Poesía completa, ed. de José Ignacio Díez Fernández, Barcelona, Planeta, 1989.

${ }^{3}$ Todos estos aspectos biográficos de la generación petrarquista han sido recopilados a partir de la edición, ya mencionada de: D. Hurtado de Mendoza, op. cit., 1990. No obstante, también hemos utilizado como fuente de información: Garcilaso de la Vega, Poesías completas castellanas, ed. Elías Rivers, Madrid, Clásicos Castalia, 1996, pp. 12-18.
} 
como un arcaísmo, y por lo tanto como un de signo de inadaptación al arte nuevo. Todo ello, teniendo en cuenta la formación poética del poeta, la tradición literaria en la que se educa y sus rasgos poéticos personales.

Pero para ahondar en esos rasgos de inadaptación e innovación que pudieran aparecer soterrados bajo los sonetos de Hurtado de Mendoza, necesitaremos puntualizar cuales son los rasgos comunes y divergentes que mantiene con los poetas de su generación. Y todo ello, teniendo en cuenta que no se trata de encontrar diferencias tajantes, aunque a veces sí exclusivas de este poeta; sino, las más de las veces, de pequeños rasgos que sugieren un proceso de asimilación, de evolución y de inadaptación a una nueva forma de hacer poesía.

Por otra parte, pretendemos dejar claro que nuestro objetivo no ha sido el de estudiar la incorporación de nuevos conceptos, metáforas y maneras de expresar propias de la manera petrarquista; pues parece que para los poetas castellanos fue más fácil la adaptación a estos conceptos petrarquistas - algunos de lejana ascendencia, ya presentes en la poesía trovadoresca - que el habituarse a una nueva estrofa, que el adaptar y limitar sus composiciones a un número de silabas distinto al que estaban acostumbrados a emplear. En fin, para los poetas castellanos fue más complicada la acomodación de su pensamiento a un nuevo verso con un tipo de tonalidad y acentuación distinta a la que estaban acostumbrados a utilizar en otro tipo de estrofas.

Por otra parte, al intentar establecer los límites del corpus de sonetos de Diego Hurtado de Mendoza, nos hemos encontrado con el inconveniente de dar con una colección de sonetos confusa, repleta de falsas atribuciones e innumerables variantes; propiciado, sin duda, por la ausencia de un manuscrito autógrafo de este autor. Parece que lo único que supervisó fue una colección de treinta y nueve textos recogidos antes de 1549, conservada en la Biblioteca Nacional de París. Todas las ediciones, hasta hoy, de las poesías de Mendoza parten de una edición princeps que sale a la luz en 1610; recientemente, Alberto Blecua ${ }^{4}$ escribió un artículo donde intenta demostrar una posible participación de Cervantes en la autoría del prólogo al lector y de los sonetos preliminares que acompañan la edición de las obras de Hurtado

\footnotetext{
${ }^{4}$ A. Blecua, «La epístola al lector a la edición de las obras de Hurtado de Mendoza (Madrid, 1610) ¿Un viejo nuevo texto cervantino?», en Ínsula, (abril-mayo 2005), pp. 2-6.
} 
de Mendoza en 1610. A pesar de esta edición, Mendoza siguió leyéndose en manuscritos hasta principios del siglo XIX. La historia de la transmisión textual moderna de Hurtado de Mendoza se reduce a la edición de Knapp en 1877, la de Bohigas en 1944, la de Batchelor en 1959 y la de Díez Fernández en 1989.

En cualquier caso, hemos delimitado el corpus utilizado a partir de la edición de Poesías Completas de Diego Hurtado de Mendoza que han editado Luis Díaz Larios y Olga Gete Carpio, ${ }^{5}$ y que reduce el corpus de sonetos de este autor a treinta y tres, una vez eliminadas las falsas atribuciones. En ocasiones hemos cotejado algunos versos que nos planteaban dudas con los de la edición de José Ignacio Díez Fernández. ${ }^{6}$

En este estudio trataremos de analizar en qué radica, a nuestro juicio, uno de los atractivos del estudio de la métrica de los sonetos de Mendoza, pues creemos que no sólo nos hallamos ante una de las primeras incursiones en el uso del endecasílabo en la literatura castellana, sino porque también encontramos en él un punto de referencia para conocer la evolución formal, el cambio de pensamiento y la adaptación a la que tuvieron que someterse los integrantes de una generación formada y educada en la poética de arte mayor castellana. Todo ello, creemos, justifica este estudio.

\section{TRAdición y NOVEDAD EN EL PROCESO DE ADAPTACión AL ENDECASílabo}

Para tener una visión adecuada de los sonetos de Diego Hurtado de Mendoza, y del uso que hace, en ellos, del endecasílabo, conviene, en primer lugar, recordar la formación del autor en el arte mayor (dodecasílabos) y arte menor (octosílabos).

Durante el siglo $\mathrm{XV}$, el dodecasílabo triunfa en la poesía cortesana y de cancioneros, pues la poesía grave de los cancioneros se escribía en copla de arte mayor. ${ }^{7}$ A la vez, el octosílabo barre en los cancioneros al heptasílabo y se impone como verso dominante en el arte menor.

A todo esto, se añade que el texto poético más importante a principios del XVI es, sin duda, el Cancionero General de Hernando del Castillo, cancionero

\footnotetext{
${ }^{5}$ D. Hurtado de mendoza, op. cit., 1990.

${ }^{6}$ D. Hurtado de mendoza, op. cit., 1989.

${ }^{7}$ Para todos estos aspectos debe acudirse a: F. Lázaro Carreter, Estudios de poética, Madrid, Taurus, 1976, pp. 75-111.
} 
que se publicó en 1511 alcanzando un extraordinario éxito en la época, puesto que se conocen hasta nueve ediciones. Esto supone, según José Manuel Blecua, «que este texto poético anduvo en manos de todos estos poetas, y que su influencia fue considerable desde Boscán a Fernando de Herrera».8

En esos primeros años del siglo XVI nacen Hurtado de Mendoza, Garcilaso, Cetina, Acuña..., coincidiendo su periodo de formación y educación con el éxito del Cancionero General. Este cancionero, posiblemente, «sirvió de referencia poética juvenil» ${ }^{9}$ para todos estos aspirantes a poeta que comenzaban en esos años a componer sus primeros versos. Algunos de ellos, herederos de la tradición cancioneril, componen coplas castellanas «siguiendo los patrones métricos cuatrocentistas». ${ }^{10}$

Probablemente, las primeras composiciones poéticas de Mendoza, al igual que los poetas de su generación, también hayan sido canciones o coplas en versos cortos al estilo cancioneril del siglo $\mathrm{XV}$, aunque resulta bastante arriesgado aventurarse a establecer una fecha fiable de la composición de estas coplas y canciones castellanas, ya que no existe ningún escrito que pueda facilitar una posible fecha de redacción. El único documento que podría, de alguna manera, justificar esa primera etapa cancioneril en Mendoza, son estas palabras de Boscán que encontramos recogidas en «la carta a la Duquesa de Soma»:

[...] En el primero avrá vuestra señoría visto esas coplas (quiero dezillo así) hechas a la castellana. Solía holgarse con ellas un hombre muy avisado y a quien vuestra señoría debe de conocer muy bien, que es Don Diego de Mendoça. Mas paréceme que se holgava con ellas como con niños, y así las llamaba las redondillas. ${ }^{11}$

Es de suponer, pues, que durante los primeros años del siglo XVI la vieja poesía, representada por el verso octosílabo, conviviese con el nuevo metro endecasílabo. Aunque hubo un momento, con el triunfo de las formas italianas (aproximadamente desde 1530) en el que el octosílabo quedó relegado a la poesía popular y tradicional.

\footnotetext{
${ }^{8} \mathrm{~J}$. M. BLecua, «Corrientes poéticas en el siglo XVI», Sobre poesía de la Edad de Oro, p. 11-24. Véase también la reciente edición de J. González Cuenca, Cancionero general; recopilación de Hernando del Castillo, Madrid, Castalia, 2004.

${ }^{9}$ Ibidem, J. M. Blecua, p. 21.

${ }^{10}$ Garcilaso compone ocho coplas castellanas. Véase. Garcilaso De La Vega, op. cit., pp. 18-19.

${ }^{11}$ Véase. J. Boscán, Obra Completa, ed, Carlos Clavería, Madrid, Cátedra, 1999, p. 115.
} 
Suele señalarse como límite de esa primera etapa cancioneril 1526,12 año en el que tiene lugar la famosa conversación entre Boscán y el humanista Andrea Navagiero durante las bodas de Carlos V e Isabel de Portugal. Esta conversación llevará a Boscán y a Garcilaso a ensayar sus primeros poemas en endecasílabos.

En el caso concreto de Diego Hurtado de Mendoza, su condición de militar y diplomático le llevó en innumerables ocasiones a Italia, donde participó en guerras (como la «Batalla de Provenza», donde, se cree, que coincidió por última vez con Garcilaso) y en asuntos diplomáticos (intervino decisivamente en el «Concilio de Trento» en 1545). Estos largos periodos en Italia (regresa, definitivamente, a España en 1561) le permitieron entrar en contacto con el humanismo italiano, convirtiéndose, así, en uno de los nobles más preparados de su época.

Seguramente, esa cercanía con la poética italiana del cincuecento hizo que Hurtado de Mendoza pronto comenzara a componer sonetos, pero para un poeta acostumbrado al octosílabo la adaptación de su pensamiento a una nueva forma métrica que exigía un número de sílabas distinto y la pérdida de ciertos usos métricos a los que estaba acostumbrado, no debió ser tan fácil.

Por eso, partiendo de un análisis métrico trataremos de explorar las corrientes literarias que influyen y confluyen en los sonetos de Mendoza y que son, creemos, reflejo de una trayectoria de aprendizaje poético. Se trata, pues, de enumerar y clasificar los rasos que lo vinculan con la lírica tradicional del siglo XV; y cuales, por el contrario, son signos de adaptación a la medida de un nuevo verso.

\subsection{Las herencias del verso agudo}

Cuando Mendoza comienza a componer sus primeros sonetos, «la acomodación al arte nuevo» era, según Lapesa, todavía imperfecta. En esa época temprana, era frecuente que los versos endecasílabos tuviesen rimas agudas, pues no sólo sigue empleándolas Hurtado de Mendoza sino también otros poetas del primer grupo petrarquista ${ }^{13}$ como Acuña, Boscán..., a

\footnotetext{
${ }^{12}$ Véase "Carta a la Duquesa de Soma" en J. Boscán, op. cit., pp. 115-120.

${ }^{13}$ A. Gallego Morell, op. cit., p. 243. Aunque la primera vez que aparece este término es en J. G. Fucilla, «Two generations of petrarchism and patrarchists in Spain» en Modern philology, Chicago, (1930), pp. 277-295.
} 
excepción de Garcilaso. Sin embargo, esa terminación aguda del verso era, según todos los investigadores, un signo claro de inadaptación al arte nuevo.

Ahora bien, como ha estudiado Rafael Lapesa, «la relativa frecuencia con la que aparece el verso agudo en decenios inmediatos se debe a que los poetas españoles aplicaron al endecasílabo las libertades a las que estaban acostumbrados en el arte real y arte mayor tradicional, donde usaban indiferentemente las rimas llanas y agudas». ${ }^{14}$

Como decíamos, el verso agudo domina en la primera mitad del siglo XVI (excepto en Garcilaso) y, muy probablemente, su eliminación fue efecto, señala Lapesa, de una moda literaria que buscaba separarse de la tradición poética anterior, muy alejada estéticamente de la mesura del endecasílabo y unida a la lírica tradicional por esa herencia del verso octosílabo.

No obstante, según matiza Lapesa, Garcilaso utilizó ocasionalmente el verso agudo en su etapa inicial, aunque después, tan pronto como entró en pleno contacto con la poesía italiana «su fino sentido artístico» ${ }^{15}$ le hizo rechazar el final oxítono del verso. Del mismo modo, esa progresiva disminución de los finales agudos en los endecasílabos se observa en Boscán. ${ }^{16}$

No obstante, Hurtado de Mendoza parece, y así lo demuestra en la mayoría de sus endecasílabos, que se mantiene fiel a una moda, la del uso de versos oxítonos, que ya no continúa en ninguno de los poetas de su generación. Es más, él nunca prescinde del uso de los finales oxítonos, a pesar de que hacia 1550-1552, se experimenta un cambio y desaparece la rima aguda de los endecasílabos. Reproduzco parte de la exposición de Francisco Rico sobre el destierro del verso agudo:

[...] Entre 1550-1552, pues, los gustos se habían depurado a ojos vistas. Las vanguardias poéticas, no satisfechas con postergar el octosílabo, imponían leyes más rigurosas al endecasílabo. Y eran los suyos unos imperativos tan apremiantes como para que Hozes se aviniera a acatar un precepto que se le antojaba excesivo y no bien autorizado: el destierro del verso agudo. ${ }^{17}$

\footnotetext{
${ }^{14}$ R. Lapesa, Garcilaso, Estudios completos, Madrid, ISTMO, 1985, p. 185.

${ }^{15} \mathrm{Ibidem}, \mathrm{R}$. Lapesa, pp. 183-186.

${ }^{16}$ Ibidem, R.,LApesa, pp. 183-186.

${ }^{17}$ F. Rico, «El destierro del verso agudo», Estudios de literatura y otras cosas, Barcelona, Destino, 2002, p. 229.
} 
Fiel reflejo de esa obcecación de Mendoza por conjugar el verso agudo y el endecasílabo, son las epístolas que, aproximadamente hacia 1539, se envían Hurtado de Mendoza y Juan Boscán. Mendoza, desde Venecia, le remite a Boscán una epístola ${ }^{18}$ en tercetos plagada de numerosos versos agudos, utiliza más de 40 en 274 versos. Probablemente Boscán, influido por el ejemplo de Mendoza, le responde con otra carta en tercetos, donde la proporción de agudos es mayor a la de otras composiciones suyas de esa época, «emplea 18 versos agudos en 403 versos». ${ }^{19}$

En cualquier caso, estas y otras razones hicieron que Hurtado de Mendoza siempre estuviese a la cabeza entre los partidarios de aunar endecasílabo y verso agudo, persiguiéndole una fama que Hozes resumió en una frase que decía: «don Diego en mil versos los usó». ${ }^{20}$

\subsubsection{Rimas agudas en los sonetos de Mendoza}

Como ha estudiado Rafael Lapesa, y más recientemente Francisco Rico, el verso oxítono era sumamente raro en la poesía italiana, y como tal, esa terminación aguda del verso era considerada como un signo de inadaptación al endecasílabo. Sin embargo, Diego Hurtado de Mendoza, al margen de los poetas de su generación, se mantiene, como veremos, fiel al uso del verso agudo. Así lo demuestra en los treinta y tres sonetos que compone, donde muestra 51 finales oxítonos en 462 versos.

En ocho de los treinta y tres sonetos utiliza el final agudo sólo como rima en los tercetos, mientras que en otros cinco la emplea de manera desmedida, cargando los cuartetos y los tercetos de abundantes rimas agudas que saturan y endurecen el final de sus versos.

La rima aguda empleada por Diego Hurtado de Mendoza en sus sonetos, se muestra como un artificio pobre y recurrente, frente al posible caudal de rimas variadas que podrían haberle proporcionado las consonancias graves. Además, las palabras oxítonas que se muestran como final de verso en sus sonetos son, como veremos, pocas, pobres y muy obvias, pues hay una serie de agudos que usa de manera recurrente como rima en diferentes sonetos.

\footnotetext{
${ }^{18}$ D. Hurtado de Mendoza, op. cit., 1990, pp. 82-92; y J. Bóscán, op. cit., 1999.

${ }^{19}$ F. Rico, op. cit., p. 216.

${ }^{20}$ Ibidem, F. Rico, p. 217; y también en J. Cueva, Exemplar poético II, ed. Crítica de José María Reyes Cano, Sevilla, Alfar, 1986, p. 186.
} 
El caso más obvio, de rima recurrente, es el de «ocasión» que aparece rimada con «pasión» en tres sonetos diferentes, ${ }^{21}$ siendo en los tres ejemplos rimas contiguas. El ejemplo que proponemos a continuación ilustra esta rima:

Tiempo vi yo que Amor puso un deseo honesto en un honesto corazón; tiempo vi yo, que ahora no lo veo, que era gloria y no pena mi pasión

tiempo vi yo que por una ocasión d[ie]ra angustia y congoja y, si venía, señora, en tu presencia la razón me faltaba y [mi] lengua enmudecía

(Soneto XXXVII, 1-8)

Muy similar, es el caso de «corazón» y «razón» que riman entre ellas en dos sonetos. ${ }^{22}$ Esta rima logra alcanzar gran importancia, no por la frecuencia, sino por la yuxtaposición relegada a final de verso que sirve como reclamo de la atención del lector:

Amor dijo en mi primera edad: "si amares, no te cures de razón". siguió su voluntad mi corazón, mas él nunca siguió mi voluntad.

(Soneto XL, 1-4)

En otros casos, los agudos llegan a ser monótonos por proceder, mayormente, de la misma categoría lingüística, además de ser superficiales por formarse todos ellos por los mismos procedimientos morfológicos: rimas construidas con el infinitivo terminado en $-\mathrm{ar}^{23} \mathrm{o}$ en $-\mathrm{ir},{ }^{24}$ con palabras terminadas en -al, ${ }^{25}$-ás ${ }^{26} \mathrm{o}$-ción. ${ }^{27}$

\footnotetext{
${ }^{21}$ Seguimos, en todos los sonetos, la numeración que ofrecen Luis F. Díaz Larios y Olga Gete Carpio en D. Hurtado de Mendoza, op. cit., 1990: Soneto XXXVII: 1-8, Soneto XL: 5-8 y Soneto XLII: 9-14.

${ }^{22}$ Ibidem. Soneto XXXVII: 1-8 y Soneto XL: 1-4.

${ }^{23}$ Ibidem. Soneto XXXI: 9-14 y Soneto XXXVI: 1-8.

${ }^{24}$ Ibidem. Soneto XXXV: 9-14 y Soneto XXXVI: 9-14.

${ }^{25}$ Ibidem. Soneto XXXIV: 9-14 y Soneto XLIII: 9-14.

${ }^{26}$ Ibidem. Soneto XLIII: 1-8.

${ }^{27}$ D. Hurtado de Mendoza, op. cit., 1990: Soneto XLV, 1-8.
} 
Al mismo tiempo, Mendoza tampoco renuncia a utilizar los monosílabos agudos asonantes, a pesar de que resulten simples y den la sensación de estar poco elaborados, como dice Francisco Rico, «el consonante más fácil de hallar, porque tiene menos letras es el agudo».$^{28}$ Veremos a continuación un ejemplo de rima con monosílabo asonante:

Con chismerías de enojo y de cuidado

Me viene, que es peor que cuanto peno Y, si algún placer me trae, con él me va.

Como a madre con hijo regalado que, si llorando (le) pide algún veneno, tan ciega está de amor, que se lo da.

(Soneto XLI, 9-14)

Asimismo, el hecho de que Hurtado de Mendoza emplee, en el soneto $\mathrm{XLV}$, la rima aguda imperfecta, que es la que no repite exactamente la misma terminación, pone de manifiesto una vez más la poca elaboración de sus rimas:

Yo sufro y [callo] y dí[go]te, Señora: ¿cuándo será aquel día que estaré libre desta contienda en tu presencia?

Respóndeme tu saña matadora: "juzga lo que he de ser por lo que fue, que menos son tus males en ausencia".

(Soneto XLV, 9-14)

No obstante, el caso más representativo de ese afán de Hurtado de Mendoza por valerse del verso agudo es, sin duda, el que se muestra en Soneto XLIX, ya que en el segundo terceto tiene lugar una licencia métrica referida a la acentuación. Fenómeno métrico que se conoce con el nombre de diástole. Veamos el ejemplo:

Quéjome de los hados inhumanos que a tal varón hicieron tanto mal, del miedo y vileza de Cartago;

\footnotetext{
${ }^{28}$ F. Rico, op. cit., p. 238
} 
Mas quédame un consuelo en lo que hago, que él mismo se mató porque Anibal no pudieran vencer sino sus manos.

(Soneto XLIX, 9-14)

Este paso del acento a la sílaba siguiente se debe a razones de rima porque unos versos antes, en el mismo soneto, se acentúa correctamente «Aníbal». Veamos el ejemplo:

Los huesos y ceniza consagrada

de Aníbal, que ha pagado a la natura

la deuda postrimera; y yo, la armada

diosa que en batallas da ventura.

(Soneto XLIX, 6)

Hasta aquí hemos podido comprobar cómo Hurtado de Mendoza integra el verso agudo en el endecasílabo, rasgo que lo relaciona directamente con la tradición cancioneril. Sin embargo, existe aún otro rasgo en el endecasílabo español de principios del XVI que lo vinculaba con la ranciedad cancioneril, pues, como afirma Francisco Rico «las rimas oxítonas solían ser, frecuentemente, abstractas en la lírica tradicional del XV; por esa razón, muchos poetas, entre ellos Garcilaso, rechazaban el uso de rimas oxítonas abstractas». ${ }^{29}$

Para Garcilaso, el uso de estas rimas oxítonas abstractas en los endecasílabos resultaba intolerable por evocar claramente a la lírica anterior, y "por eso prefería utilizar rimas paroxítonas concretas, referidas, frecuentemente, a la naturaleza». ${ }^{30}$ No obstante $-\mathrm{y}$ como viene siendo habitual en los sonetos de Hurtado de Mendoza - nuestro poeta no renunció a utilizar los oxítonos abstractos como rima en sus sonetos. Precisamente de los 51 finales agudos de sus treinta y tres sonetos sólo cinco de ellos son concretos:

$\begin{array}{ll}\text { mas en mí este remedio no ha lugar } & \text { (Soneto XXXI, 12) } \\ \text { que el cielo dio al mundo por señal } & \text { (Soneto XXXIV, 13) } \\ \text { déjase al viento y métese a la mar } & \text { (Soneto XLIII, 11) } \\ \text { sobre el sepulcro de Áyax Telamón } & \text { (Soneto XLV, 2) } \\ \text { que él mismo se mató porque a Anibal } & \text { (Soneto XLIX, 13) }\end{array}$

\footnotetext{
${ }^{29}$ F. Rico, op. cit., p. 245.

${ }^{30}$ Ibidem, F. Rico, pp. 245-247; y K. Whinnom, «Hacia la interpretación y apreciación de las canciones del Cancionero General de 1511», Filología XIII, (1968-1969), pp. 361-381.
} 
Aparte de las rimas oxítonas abstractas, un estudio de Keith Whinnom ${ }^{31}$ ha mostrado que de los 297 sustantivos diferentes encontrados en el Cancionero de Hernando del Castillo, los que más aparecen son: «passión vida, mal, dolor, muerte, esperanza, razón, gloria, corazón, amor, fe, ventura, plazer, bien, tormento, remedio, temor, tristura, morir, causa y pensamiento». ${ }^{32}$ Formando, todas estas palabras parte del vocabulario cancioneril. Quizá por esa razón, Garcilaso jamás utilizó «passión» como rima en sus versos endecasílabos.

No obstante, la influencia que la lírica tradicional cancioneril ejerce sobre los sonetos de Hurtado de Mendoza no se limita al uso «rancio» de ciertos usos métricos, como la rima aguda, sino que también se observan en sus versos numerosos procedimientos formales y estilísticos vinculados al arte de cancionero. Por lo tanto, no es extraño que sus sonetos presenten un uso notable de la rima «pasión». ${ }^{33}$ A pesar de que ya era considerada, por sus coetáneos, como un rasgo arcaico utilizarla en la innovadora métrica de origen italiano.

Asimismo, emplea otras palabras propias del vocabulario cancioneril: «mal, amor, corazón, razón» ${ }^{34}$ como rima en sus sonetos.

Después de todo lo anterior, parece posible poder sostener que existe una vinculación clara entre los sonetos de Mendoza y el arte de cancionero, pues encontramos en los versos de Mendoza el vocabulario característico del Cancionero: «oxítono y abstracto». ${ }^{35}$ Consecuentemente, todo ello parece indicar que las divergencias observadas entre Mendoza y los otros poetas de su generación con respecto al uso del verso agudo, estriban, en mayor medida, en cuestiones ideológicas, que muestran que en Hurtado de Mendoza no existe una verdadera ruptura con los temas y formas métricas heredadas del arte cancioneril anterior.

Así pues, los resultados de este análisis confirman las principales tendencias del estilo poético de Hurtado de Mendoza. Hemos comprobado que el afán de novedad que impulsa a Mendoza a crear en endecasílabos está lastrado por antiguas resonancias de la lírica cancioneril.

${ }^{31}$ Ibidem. K. Whinnom, pp. 361-381.

${ }^{32}$ F. Rico, op. cit., p. 246.

${ }^{33}$ Soneto XXXVII: 1-8, Soneto XL: 6-7, Soneto XLII: 9-14.

${ }^{34}$ Soneto XXXVII: 2-7; Soneto XL, 2-3; Soneto XLIII, 13 y Soneto XXXVII, 9.

${ }^{35}$ F. Rico, op. cit., pp. 245-247. 


\subsection{Signos de adaptación al nuevo metro: el endecasílabo.}

En líneas generales, la revolución métrica que propicia el endecasílabo en la poesía española no equivale a la renuncia y pérdida de rasgos y costumbres métricas de la lírica anterior, o por lo menos, no por completo en todos los poetas. Por lo tanto, es lógico pensar que Diego Hurtado de Mendoza como principiante en el uso del endecasílabo tropezase con obstáculos (irregularidades métricas, versos hipermétricos) en sus inicios. Obstáculos que sólo podría superar y corregir con esfuerzo y dedicación.

Probablemente, de esa inexperiencia con el endecasílabo es como surgen los versos hipermétricos ${ }^{36}$ que encontramos en algunos sonetos:

$$
\begin{array}{lll}
\text { Y, si algún placer me trae, con él me va } & 11+1 & \text { (Soneto XLI, 11) } \\
\text { Por brava playa con recio temporal } & 11+1 & \text { (Soneto XLIII, 10) }
\end{array}
$$

Del mismo modo, debemos interpretar todas las licencias métricas que emplea Diego Hurtado de Mendoza en sus sonetos, pues las utiliza para adaptarse a las once sílabas que le exigía el nuevo metro.

Llegado a este punto, conviene hacer algunas matizaciones sobre el análisis que vamos a hacer de las licencias métricas empleadas por Hurtado de Mendoza en sus Sonetos, pues sólo daremos cabida en el análisis a aquellas que sean más representativas, más singulares, las que puedan llegar a particularizar la técnica poética de Mendoza respecto a la de otros poetas de su generación. A la vez que desestimaremos todas aquellas que por ser tan generales, no servirían para poder establecer diferencias.

En este sentido, especialmente significativo resulta el uso de la sinéresis y diéresis en sus endecasílabos.

\footnotetext{
${ }^{36}$ En la edición que seguimos, y que editan Luis F. Díaz Larios y Olga Gete Carpio, sólo se registran las variantes que coinciden en más manuscritos, al margen de cualquier consideración estética. En cambio, en la edición José Ignacio Díez Fernández, al no ser crítica, no tiene en cuenta esos mismos criterios para fijar las variantes de los versos. Por esa razón, esos dos versos hipermétricos, de los que hablamos, se convierten en esta última edición en endecasílabos correctos.
}

Así los versos pasan a ser endecasílabos:

Y si algún bien me trae, con él me va. $10+1$

Por brava playa en recio temporal $\quad 10+1$

En cambio, en la edición de José Ignacio Díez Fernández aparece otro verso hipermétrico, que no lo es en la edición de Luis F. Díaz Larios y Olga Gete Carpio:

Pena ni gloria, descanso ni tormento 


\subsubsection{Sinéresis}

Para comprender las razones por las que Hurtado de Mendoza utiliza la sinéresis, tendremos en cuenta, en primer lugar, la incidencia que tiene esta licencia métrica en sus versos; si esa aparición responde a un desconocimiento del hiato, o por el contrario, sólo se muestra como un recurso para alcanzar las once sílabas; si su utilización responde a razones estéticas o a un mal manejo del endecasílabo.

Este recurso - la sinéresis - se manifiesta en 15 de los 462 versos que tienen los sonetos de Diego Hurtado de Mendoza, uniendo en diptongo a las vocales -ae, -ía y -ea. No es extraño, pues, encontrar ejemplos donde esta licencia métrica alcance cierta extensión en un mismo verbo:

$\begin{array}{ll}\text { Traeme ciego de verdad en verdad } & \text { (Soneto XL, 5) } \\ \text { y si algún placer me trae, con él me va } & \text { (Soneto XLI, 11) } \\ \text { que nos traes embaucados tierra y cielo } & \text { (Soneto XCV, 2) }\end{array}$

Sin embargo, se advierten diferencias que desestiman que este hiato, en el verbo traer, fuese desconocido por Mendoza, ya que no hace sinéresis con el verbo traer en los versos siguientes:
Tra-é-me amor de pensamiento vano
(Soneto XXXIX, 1)
Y trá-e-nos el seso a la redonda
(Soneto XCVI, 10)

En ocasiones, la sinéresis alcanza gran difusión, incluso, dentro del mismo soneto. Como es el caso del hiato -ía que se convierte en diptongo en seis ocasiones, requiriendo de una gran habilidad para su articulación. El siguiente ejemplo puede resultar representativo:

$\begin{array}{ll}\text { chismerías de enojo y de cuidado } & \text { (Soneto XLI, 9) } \\ \text { en las otras ropas lo había echado } & \text { (Soneto XLVI,7) } \\ \text { no alcanzaría más luz su señoría } & \text { (Soneto XCVI, 13) }\end{array}$

No obstante, este uso de la sinéresis tampoco responde a un desconocimiento del hiato, ya que es frecuente que -ía sea considerado como hiato. Como por ejemplo en: dí-as (Soneto XXXI), dí-a (Soneto XXXIII), tení-a (Soneto XXXIV), parecí-a (Soneto XXXIV), crí-a (Soneto XXXV), porfí-a (Soneto $X X X V)$, dí-a (Soneto XXXVI)... 
Por último, es interesante mencionar la presencia de otra modalidad de sinéresis, la que afecta al hiato -ea. Siendo especialmente recurrente en la forma verbal sea:

$$
\begin{array}{ll}
\text { tibio en amores no sea yo jamás } & \text { (Soneto XLIII 1) } \\
\text { sea limosna o sea piedad siquiera } & \text { (Soneto LII, 3) } \\
\text { cortada sea la mano que te diere } & \text { (Soneto CXIX, 1) }
\end{array}
$$

Estos versos, en los que aparece la sinéresis como recurso, parecen confirmar que esta licencia métrica en Mendoza sólo se muestra como una técnica para alcanzar la medida exacta del endecasílabo. Aunque hay quienes como Ricardo James Freire condenan el uso de la sinéresis como posibilidad estilística, hasta el punto de decir que «no existe verso bueno con ella». ${ }^{37}$

\subsubsection{Diéresis}

La diéresis, al contrario que la sinéresis, consiste en la separación de las dos vocales de un diptongo, así cada vocal cuenta con valor silábico. ${ }^{38}$ Considerándola en cuanto a la técnica del verso, es un recurso que posiblemente utiliza Mendoza para conseguir el número de sílabas exacto en la medición de los versos que le resulten defectuosos.

Siguiendo el mismo método que el utilizado para el análisis de la sinéresis, debemos comenzar por decir que la diéresis es empleada en 16 de los 462 versos que constituyen sus sonetos.

En algunos versos la diéresis se reconoce fácilmente porque está señalada, en ediciones modernas, con un signo diacrítico llamado crema ["]. En consecuencia, el diptongo -ue se deshace, y se convierte en un elemento más para conseguir alcanzar las once sílabas:

$$
\begin{array}{ll}
\text { por qué sois tan crü-el, siendo tan tierno } & \text { (Soneto XCVII, 10) } \\
\text { a esta fiera crü-el amando sigue } & \text { (Soneto XXXVIII, 2) } \\
\text { oh jü-ez sin razón ni fundamento } & \text { (Soneto XLVI, 11) }
\end{array}
$$

Sin embargo, el diptongo -ue se mantiene como tal en varias ocasiones. Sirvan de ejemplo algunas, como: Dueño (Soneto XXXI), Sueño (Soneto XXXI), Fue (Soneto XXXIII), Duele (Soneto XXXII), Muerte (Soneto XXXII) etc.

\footnotetext{
${ }^{37}$ J. Domínguez Caparrós, Diccionario de métrica española, Madrid, Paraninfo, 1992, pp. 69-70.

${ }^{38}$ R. Baehr, Manual de versificación española, Madrid, Gredos, 1975, pp. 42-47.
} 
Frente a este uso de la diéresis, surge otro que ocupa un lugar más destacado y numeroso en sus versos, pues en ocasiones nos encontramos con que esta licencia métrica se utiliza como un recurso para establecer la rima perfecta del final de sus versos; además de proporcionar la medida exacta de los mismos. Este uso se observa muy claramente en los siguientes versos:

mas puso lo peor, pues el penar me hace por razón desvari-ar

(Soneto XXXVI, 6-7)

Aunque el uso más singular de la diéresis es, sin duda, el que se produce en «confianza» siempre que rima con «mudanza»:

combaten el recelo y confi-anza

asegurale fe toda mud-anza

(Soneto XXXIII, 6, 7)

alzóse una borrasca de mud-anza

quisieran castigar mi confi-anza

(Soneto XLVII, 11, 13)

ansí, que ya sin bien, sin confi-anza

podría ya muy bien hacer mud-anza

(Soneto LIII, 9, 11)

Aunque en otras dos ocasiones, «confianza» rima con «esperanza» haciendo también diéresis en la primera de ellas:

tanto sería de vana esta esper-anza

que no es bien de afligidos confi-anza

(Soneto XL, 14)

la vana fantasía y confi-anza

y confiado vivir sin esper-anza

(Soneto XLII, 9,14)

La única vez en la que «confianza» no hace diéresis es en un derivado suyo, «confiado». Como se puede observar en:

y confiądo vivir sin esper- anza

(Soneto XLII, 9, 14) 
Las razones por las que Hurtado de Mendoza emplea la diéresis pueden ser muchas y muy variadas, aunque sobre todas ellas, sobresale la que la confirma como un recurso del que se vale para adaptarse a la medida del endecasílabo. Sin embargo, son muchos los ejemplos que demuestran que también es un recurso al que acude para establecer la rima perfecta en el final de sus versos:

Veo venir el mal, no sé hu- ir

Que puedo yo esperar del porven-ir

(Soneto XXXVI, 9, 12)

\subsubsection{Otras licencias}

Para lograr la medida exacta del endecasílabo, Mendoza emplea, como ya hemos visto, «dudosas licencias métricas». Por tanto, no nos debería ser extraño que sus versos presenten un notable incremento de recursos para reducir o aumentar el número de sílabas. Por esa misma razón, y como viene siendo habitual, no es extraño localizar en los versos de Hurtado de Mendoza «metaplasmos». Los ejemplos que proponemos a continuación ilustran este punto, pues en los sonetos de Mendoza es habitual encontrar apócopes que reducen el número de sílabas. Tales como:

$\begin{array}{ll}\text { y que sabe cuán poco bien espera } & \text { (Soneto LI, 11) } \\ \text { ¡Cuán presto pasa un temple del verano } & \text { (Soneto LVIII, 9) } \\ \text { y cuán despacio destemplados tiempos } & \text { (Soneto LVIII, 10) } \\ \text { Y toda la aspereza por do he andado } & \text { (Soneto LIII, 5) } \\ \text { Do por la muerte dejaré de haberos } & \text { (Soneto LV, 10) } \\ \text { entre gentes extrañas do se encierra } & \text { (Soneto LVII, 9) } \\ \text { en el mar, en el cielo, so la tierra } & \text { (Soneto LVII, 12) }\end{array}$

Sin embargo, otras veces aparece la forma sin apocopar; en el mismo soneto:

y cuánto cuesta un bien no conocido!

(Soneto LVIII, 11)

Por este motivo no debe sorprendernos que - salvando las diferencias las licencias métricas utilizadas en unos y otros casos sean similares. Por esa razón, otro de los procedimientos empleado para incrementar el numero de sílabas de un verso es la «prótesis». Lo podemos observar en: 
Abájelos en lágrimas bañadas

(Soneto XLVII, 4)

vi entre las nueve hermanas asentada

una hermosa ninfa al diestro lado

(Soneto XXXIV, 3-4)

Por otra parte, y al margen de la función específica y habitual de la sinalefa, en los versos de Mendoza se observa una incipiente tendencia al enlace de las vocales con la conjunción «y». Lo que Rafael Balbín denomina como «sinalefa consonántica» ${ }^{39}$ porque se considera la conjunción «y» como una semivocal o semiconsonante:

$\begin{array}{ll}\begin{array}{l}\text { amor lo dio y amor pudo quitallo } \\ \text { vuelve el cielo, y el tiempo huye y calla }\end{array} & \begin{array}{l}\text { (Soneto XXXII, 12) } \\ \text { crece el deseo y mengua la esperanza }\end{array} \\ \begin{array}{l}\text { (Soneto XXXIII, 3) } \\ \text { yo sufro y callo y dígote, señora } \\ \text { en la fuente más clara y apartada }\end{array} & \text { (Soneto XXXIII, 9) } \\ \text { y en la causa del mal se le convierte; } & \text { (Soneto XLII, 4) } \\ \text { sin muerte y conocida sepultura, } & \text { (Soneto XLIV, 7) } \\ \text { acuerdas de engañarlos y escondella, } & \text { (Soneto XLIV, 12) } \\ \text { y entregando a la vil y flaca lengua } & \text { (Soneto XLV,13) } \\ \text { y el loco mar enmiende la sentencia } & \text { (Soneto XLVI, 14) }\end{array}$

Sin embargo, este procedimiento no llega a alcanzar el grado de técnica habitual y constante; pues, no la hace continuamente, y jamás hace sinalefa cuando una palabra termina en $-\mathrm{y}$ :

que finja yo que estoy en tu memoria (Soneto $X L, 12$ )

Algo parecido se observa con las conjunciones «e»y «o» que hacen sinalefa en algunos versos, dando lugar a lo que Navarro Tomás designa como «sinalefa violenta»:40

me parece pesado e inhumano

(Soneto XXXIX, 8)

fuera de humana forma o accidente (Soneto LI, 13)

lo que una vez la fuerza o la destreza (Soneto LII, 9)

cualquiera beneficio mengua o crece (Soneto LII, 5)

\footnotetext{
${ }^{39}$ R. Balbín Lucas, Sistema de rítmica castellana, Madrid, Gredos, 1975, pp. 81-84.

${ }^{40}$ J. Domínguez Caparrós, op. cit., pp. 88-90.
} 
Estas son en resumen, las principales características del endecasílabo en los sonetos de Diego Hurtado de Mendoza: por una parte, su uso destacado del verso agudo, uso que conlleva grandes diferencias formales con los restantes poetas de su generación, más partidarios de desligarse por completo de ese resto del verso octosílabo; por otra, su utilización de licencias métricas, algunas de ellas muy criticadas, y que en último caso evidencian una poesía descuidada, lastrada de antiguas resonancias de la lírica del XV; todo ello, con cierta rudeza técnica que subraya el papel precursor y transitorio de sus sonetos dentro de la literatura española del XVI.

\section{Proceso de adaptación al ritmo acentual del endecasílabo}

El acento métrico es un elemento fundamental en el ritmo del verso ya que de la posición de las sílabas acentuadas depende en gran parte la belleza del verso y de la estrofa. Por esta razón, a lo largo de las décadas varios investigadores han propuesto diferentes modelos de explicación de la forma en la que se organiza el acento en el verso. Esos modelos podrían clasificarse, según Domínguez Caparrós, ${ }^{41}$ esencialmente en tres: Sistema de cláusulas rítmicas de Andrés Bello, El modelo Musical de Navarro Tomás y el Sistema de análisis binario de Rafael Balbín.

Sin embargo, y aunque no vamos a entrar en disquisiciones más detalladas acerca de la validez de las anteriores clasificaciones, debemos decir que éstas no han sido suficientes para el análisis acentual de los versos de Diego Hurtado de Mendoza. Por esta razón, y para suplir las carencias que nos originaban las antiguas clasificaciones del acento castellano hemos recurrido al sistema que ha propuesto recientemente Pablo Jauralde ${ }^{42}$ en su Manual de métrica española. Esta última propuesta nos permite hacer una clasificación más particularizada de la acentuación de los endecasílabos y un desarrollo más eficaz del análisis del ritmo acentual de los sonetos de Mendoza.

\footnotetext{
${ }^{41}$ P. Jauralde Pou, E. Varela Merino y P. Moíño Sánchez, Manual de Métrica española, Madrid, Castalia Universidad, 2005.

${ }^{42}$ Durante el reinado de Juan II, Castilla vive unos años de esplendor demográfico y económico, facilitado por el incremento de las exportaciones de lana, hierro y vino a los mercados europeos. Esta buena situación permite el desarrollo de instituciones que prefiguran el Estado moderno. Por otra parte, el interés del monarca por la cultura permite el surgimiento de poetas y literatos cortesanos, protegidos personalmente por el Rey.
} 
Acontinuaciónnosocupamosyadecuestiones directamenterelacionadas con la acentuación de los endecasílabos de Hurtado de Mendoza. Para ello conviene recordar que durante el periodo medieval la versificación española, hasta entonces dominada por el dodecasílabo y octosílabo, evoluciona con la paulatina incorporación de nuevas y distintas culturas a la nuestra. ${ }^{43}$ A este periodo, corresponde la primera muestra de endecasílabo en castellano, ya que por esos años, el Marqués de Santillana ensaya con endecasílabos a la italiana componiendo Cuarenta y dos sonetos fechos al itálico modo. ${ }^{44}$

A este respecto, conviene señalar que pese a que los endecasílabos del Marqués de Santillana suelen relegarse por ser rudimentarios, lo cierto es que Santillana era un gran conocedor de la poesía de Petrarca, dado que en la «Carta a doña Violante de Prades» ${ }^{45}$ demuestra tener grandes conocimientos teóricos sobre el soneto, tal y como se puede leer en aquel texto fechado el 4 de mayo de 1443:

[...] Enbíovosla, Señora, con Palomar, e asimesmo los çiento proverbios míos e algunos otros sonetos que agora nuevamente he començado a fazer al itálico modo. E esta arte falló primero en Italia Guido Cavalgante, e después usaron d'ella Checo d'Ascholi e Dante; mucho más que todos Francisco Petrarca, poeta laureado.

Además, Íñigo López de Mendoza también da muestras de conocer datos biográficos y bibliográficos sobre Petrarca. Continúa Santillana en el «Proemio a la carta»:46

[...] El Rey Roberto de Nápol, claro e virtuoso príncipe, tanto esta ciencia le plugo que, commo en esta misma sazón miçer Francisco Petrarca, poeta laureado, floreciese, es cierto grand tiempo lo tuvo consigo en el Castil Novo Nápol, con quien él muy a menudo confería e platicava d'esas artes, en tal manera que mucho fue avido por açepto a él e grand privado suyo; e allí se dize aver él fecho muchas de sus obras, así latinas commo vulgares, e entre las otras el libro "De rerum memorandorum" e las sus églogas e muchos sonetos, e en especial aquel que fizo a la muerte de este mismo rey, que comiença:

"Rota è l'alta columpna e el verde lauro", etc.

${ }^{43}$ I. López de Mendoza, Poesías completas, ed. Maxim P.A.M Kerkhof y Ángel Gómez Moreno, Madrid, Clásicos Castalia, 2003, pp. 32-34.

${ }^{44} \mathrm{Ibidem}$. I. López de Mendoza, p. 640.

${ }^{45}$ I. López de Mendoza, op. cit., p. 674.

${ }^{46}$ R. Lapesa, La obra literaria del Marqués de Santillana, Madrid, ínsula, 1957, p. 197. 
Ya sabemos que Iñigo López de Mendoza fue el primer poeta español que compuso sonetos (adelantándose casi un siglo a Boscán y Garcilaso), sin embargo y, pese a que como hemos podido comprobar el Marqués de Santillana conocía los sonetos de Petrarca, nunca logró adaptarse a una nueva forma métrica tan ajena a la tradición lírica castellana, tal y como demuestra Lapesa en La obra literaria del Marqués de Santillana. ${ }^{47}$

Según ha señalado Lapesa, en La obra literaria del Marqués de Santillana, los endecasílabos de Santillana eran rudimentarios y poco logrados, ya que en ellos seguían predominando como base rítmica acentual el ritmo dactílico [4. ${ }^{\text {, }}$ 7. ${ }^{\mathrm{a}}, 10{ }^{\mathrm{a}}{ }^{\mathrm{a}}$ y sáfico difuso, es decir los que buscan su primer apoyo en la cuarta sílaba.

No sorprende, entonces, que se observe claramente en sus sonetos ritmo más propio de la copla de arte mayor que del nuevo verso endecasílabo:

Sitio de amor con grand artillería $\left[1 .^{\mathrm{a}} 4 .^{\mathrm{a}} 10{ }^{\mathrm{a}}\right]$ Sáfico difuso pleno me veo en torno e poder inmenso, $\left[2 .^{\text {a }} 4 .^{\text {a }} 8 .^{\mathrm{a}} 10 .^{\mathrm{a}}\right]$ e jamás cessan de noche e de día, [3. . $\left.^{\text {a }} 7 .^{\mathrm{a}} 10{ }^{\mathrm{a}}\right]$ Extrarrítmico dactílico puro nin el ániño mío está suspenso $\quad\left[2\right.$. $^{\mathrm{a}} 5$. $^{\mathrm{a}} 8$. $\left.^{\mathrm{a}} 10{ }^{\mathrm{a}}\right]$

de sus combates con tanta porfía $\quad\left[4 .^{\mathrm{a}}{ }^{7}{ }^{\mathrm{a}} 10\right.$ 10 a $\left.{ }^{\mathrm{a}}\right]$ Dactílico puro que ya me sobra, maguer me deffenso, $\quad\left[4 .{ }^{\text {a }} 7 .^{\mathrm{a}} 10 .^{\mathrm{a}}\right]$ Dactílico puro Pues, ¿qué farás?, ¡o triste vida mía! [2. $\left.{ }^{\mathrm{a}} 4 .^{\mathrm{a}} 6 .^{\mathrm{a}} 8 .^{\mathrm{a}} 10{ }^{\mathrm{a}}\right]$ ca non lo alcanço por mucho que pienso. [4. $\left.{ }^{\mathrm{a}}{ }^{\mathrm{a}}{ }^{\mathrm{a}} 10{ }^{\mathrm{a}}\right]$ Dactílico puro

La corpórea fuerça de Sansón, [3. ${ }^{\mathrm{a}} 6$. $\left.^{\mathrm{a}} 10{ }^{\mathrm{a}}\right]$ nin de David el grand amor divino, [4. $\left.{ }^{a} 8 .^{a} 10 .^{a}\right]$ el seso nin saber de Salomón, [2. ${ }^{\mathrm{a}} 6$. $\left.^{\mathrm{a}} 10{ }^{\mathrm{a}}\right]$

nin Hércules se falla tanto digno $\left[2 .^{\mathrm{a}} 6 .^{\mathrm{a}} 10 .^{\mathrm{a}}\right]$ que resistir podiessen tal prisión; $\quad\left[4^{\mathrm{a}} \cdot 6^{\mathrm{a}} \cdot 10^{\mathrm{a}}\right]$ assí a deffensar me fallo indigno $\quad\left[2 .^{\mathrm{a}} 6\right.$. $\left.^{\mathrm{a}} 8{ }^{\mathrm{a}} 10{ }^{\mathrm{a}}\right]$

(Marqués de Santillana, Soneto IV) ${ }^{48}$

En definitiva, el Marqués de Santillana nunca logró desprenderse del influjo del arte mayor castellano. De hecho, del análisis métrico de Lapesa se desprende que: «Un 41,2 por 100 de los versos presenta una acentuación

\footnotetext{
${ }^{47}$ I. López de Mendoza, op. cit., p. 150.

${ }^{48}$ R. Lapesa (1957), op. cit., p. 197.
} 
propia del verso de arte mayor castellano, al igual que muchos sonetos de final del Duecento, vale decir, predantescos; del mismo modo la disposición más frecuente de las rimas corresponde al patrón del soneto italiano primitivo». ${ }^{49}$

Sin embargo, durante el Renacimiento la «primera generación petrarquista», con Garcilaso a la cabeza, desterró el ritmo dactílico de los endecasílabos por ser un ritmo demasiado machacón, y lo reemplazaron por un ritmo mucho más flexible.

Es a partir de 1526, y sobre todo, desde que Garcilaso se decide a componer en metros italianos cuando el «ritmo del endecasílabo se sostiene sobre tres o cuatro apoyos rítmicos esenciales que son, además del obligado en décima, los de cuarta, sexta y octava, siendo el primer apoyo variable». ${ }^{50}$

No obstante, no todos los poetas de principios del XVI se adaptaron con la misma facilidad que Garcilaso al ritmo acentual que exigía el nuevo metro. En el caso de Hurtado de Mendoza, ya hemos comprobado en el epígrafe anterior la estrecha relación que guardan sus endecasílabos con la lírica tradicional anterior. Por este motivo, a continuación expondremos y explicaremos cómo Mendoza reproduce esquemas y ritmos acentuales utilizados previamente por el Marqués de Santillana, sin duda, un rastro claro de la herencia del arte cancioneril que se observa sus endecasílabos.

\subsection{Esquemas acentuales: endecasílabo Dactílico y Sáfico difuso}

De acuerdo con lo visto hasta el momento, mantener el ritmo dactílico en los endecasílabos era un rasgo claro de influencia del ritmo del arte mayor castellano, tal y como lo demuestra Lapesa ${ }^{51}$ en el análisis de los endecasílabos del Marqués de Santillana. Pero, ¿qué factores influyeron en Hurtado de Mendoza para que utilizase ese mismo ritmo dactílico en sus endecasílabos? Llegados a este punto conviene hacer un breve repaso del verso de arte mayor que triunfa en esos momentos en la poesía castellana.

\footnotetext{
${ }^{49}$ P. Jauralde Pou, y otros, op. cit., pp. 371-372.

${ }^{50}$ R. Lapesa, op. cit., Rafael (1957), p. 197.

${ }^{51}$ F. Lázaro Carreter, Estudios de poética, Madrid, Taurus, 1976, pp. 75-120. Reproduzco parte de la explicación de Lázaro Carreter sobre la acentuación del dodecasílabo: «Pensamos que la verdadera vía para interpretar el enigmático metro es la abierta por Foulché-Delbosc, tal como ha profundizado Pierre Le Gentil. Rechaza, por supuesto, la existencia de hemistiquios de un sólo acento: todos cuentan con dos, si bien el primero, separado siempre por dos sílabas átonas del segundo, "ne sonne pas toujours avec une grande intensité"».
} 
En el dodecasílabo era frecuente un característico ritmo acentual de cuatro sílabas tónicas separado cada una de ellas por dos átonas [óoo óoo óoo óoo], lo que «le confería una característica presencia solemne y monótona». ${ }^{52}$ El ritmo resultante era dactílico y se articulaba en torno a cuatro ejes rítmicos. Sin embargo, ese ritmo insistente del dodecasílabo era considerado como arcaico por los poetas de principios del XVI.

A pesar de todo esto, Mendoza sigue reproduciendo los esquemas y ritmos acentuales (dactílicos y sáficos difusos) utilizados por el Marqués de Santillana casi un siglo antes. Por lo tanto, debemos interpretar del mismo modo ese uso del ritmo dactílico y sáfico difuso en el Marqués de Santillana y en Hurtado de Mendoza.

No obstante, y aunque Garcilaso se mantiene al margen de esta acentuación dactílica en la mayoría de sus versos, existen algunos ejemplos en los que muestra todavía ese ritmo dactílico perfecto. Así lo estudia José Montero Reguera en el primer soneto: «el poema se inicia con un ritmo predominantemente sáfico, propio para la exaltación lírica, con alternancia en los versos acentuados en $6 .^{\mathrm{a}}-10 .^{\mathrm{a}}$ y los acentuados en $8 .^{\mathrm{a}}-10{ }^{\mathrm{a}}{ }^{\mathrm{a}}$, si bien predominan estos últimos. Este ritmo se extiende a lo largo de los diez primeros versos a excepción del tercero, dactílico $\left(1 .^{\mathrm{a}}-4 .{ }^{\mathrm{a}}-7{ }^{\mathrm{a}}-10{ }^{\mathrm{a}}\right)$, modalidad esta utilizada por Garcilaso en muy pocas ocasiones». ${ }^{53} \mathrm{Tal}$ y como podemos observar en:

Cuando me paro a contemplar mí estado y a ver los pasos por dó me han traído, hallo, según por do anduve perdido,[1. 4. 7.10] Dactílico perfecto que a mayor mal pudiera haber llegado;

(Garcilaso, Soneto I, 1-4)

Sin embargo, debemos insistir que este ritmo dactílico es más fácil de localizar en los endecasílabos de Diego Hurtado de Mendoza que en cualquier otro poeta de principios del XVI, ya que como veremos más adelante, en sus sonetos se observan otras características rítmicas (como la acentuación en 5. ${ }^{\text {) }}$ que suponen un punto de inflexión con los poetas de su generación.

\footnotetext{
${ }^{52} \mathrm{~J}$. Montero Reguera, «En torno a un soneto garcilasiano de Lope de Vega», Actas del XIII congreso de la Asociación Internacional de Hispanistas, Madrid, Castalia, 2000, pp. 616-622.

${ }^{53}$ P. Jauralde Pou y otros, op. cit., p. 43.
} 
Los poetas coetáneos a Mendoza, rechazaban, inicialmente, los endecasílabos con ritmo dactílico ([4. $\left.\left..^{\mathrm{a}} 7 .^{\mathrm{a}} 10{ }^{\mathrm{a}}\right]\right)$ en cualquiera de sus variedades,

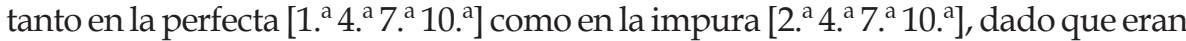
«ritmos del verso de arte mayor que sonaban a viejo». ${ }^{54}$ En este sentido, resulta muy significativo el análisis de estos versos de Diego Hurtado de Mendoza:

- Sáfico difuso pleno $\left[1 .^{\mathrm{a}} 4 .^{\mathrm{a}} 10 .{ }^{\mathrm{a}}\right]$ tiempo vi yo que por una ocasión

(Soneto XXXVII, 5)

- Sáfico difuso $\left[4 .^{\mathrm{a}} 10 .^{\mathrm{a}}\right]$ que nos encubres tanta hermosura (Soneto XLIV, 2)

- Dactílico puro $\left[4 .^{\mathrm{a}} 7 .^{\mathrm{a}} 10 .^{\mathrm{a}}\right]$ Aunque en miralla no falta cansuelo (Soneto XLIV, 8) La cual deseo ya más que ninguna (Soneto LVI, 10)

- Variante extrarrítmica del endecasílabo dactílico [1. $\left.3 .{ }^{\mathrm{a}} 4 .{ }^{\mathrm{a}} 7{ }^{\mathrm{a}} 10{ }^{\mathrm{a}}\right]$ tiempo vi yo que por una ocasión

(Soneto XXXVII, 5)

\subsection{Serie de endecasílabos no tradicionales ${ }^{55}$}

Agrupamos bajo este epígrafe una serie de ejemplos variados con ritmos poco frecuentes en el endecasílabo. La mayoría son los que carecen de acento esencial entre $2 .^{a}$ y $7 .^{a}$, entre $3 .^{a}$ y $8{ }^{a}$, o los que llevan el acento rítmico en $5 .^{a}$ sílaba.

Llegado a este punto conviene hacer algunas matizaciones. Dado que los manuales de métrica más conocidos no siempre explican los casos más extraños de acentuación, a pesar de que casi todos coinciden en una posible influencia del ritmo del dodecasílabo y/ o del octosílabo en estos versos «no tradicionales». Por lo tanto, los estudiaremos, simplemente, como ritmos que no se han naturalizado en la versificación española.

Esa serie de ritmos «no tradicionales» se recogerán en varios apartados en los que estudiaremos los endecasílabos acentuados $5 .^{a}$, en $7 .^{a}$, y en $8 .^{a}$.

\footnotetext{
${ }^{54}$ Según Jauralde son la mayoría de ritmos que dejan sin acento esencial entre $1 .^{\mathrm{a}}$ y 7 . $^{\mathrm{a}} ;$ y entre $3 .^{\mathrm{a}}$ y $8 .{ }^{\mathrm{a}}$, o que llevan un acento en $5 .^{\mathrm{a}}$. Jauralde los denomina "Serie de endecasílabos no tradicionales", mientras que Henríquez Ureña se refiere a muchos de ellos como ejemplos de “mayores libertades". P. Jauralde Pou, op. cit., pp. 196-200; y P., Henríquez Ureña, La versificación irregular en la poesía española, Madrid, 1920.

${ }^{55}$ P. Jauralde Pou y otros, op. cit. pp. 196-199.
} 


\subsubsection{Endecasílabos con acentuación en quinta}

Todos los endecasílabos acentuados en $5 .^{a}$ suelen resultar impropios, pero de entre las muchas variedades con acento en quinta posición, la más extraña es la de $\left[1 .{ }^{a} 5{ }^{a}{ }^{\mathrm{a}} 10{ }^{\mathrm{a}}\right]$. Acentuación que aparece en uno de los versos de Mendoza:

- $\left[1 .{ }^{\mathrm{a}} 5 .^{\mathrm{a}} 10 .^{\mathrm{a}}\right]$ ahora con la mano y el sentido (Soneto LVII, 3).

Abundan también los casos en los que se produce un uso variado de estos ritmos con acento esencial en quinta. Como en:

- $\left[1 .{ }^{\mathrm{a}} 3 .^{\mathrm{a}} 5 \cdot^{\mathrm{a}} 10 .^{\mathrm{a}}\right]$ ahora el alma atenta y desvelada (Soneto LVII, 6)

- $\left[2 .^{\mathrm{a}} 5 .^{\mathrm{a}} 8 .^{\mathrm{a}} 10 .^{\mathrm{a}}\right]$ o $\left[2 .^{\mathrm{a}} 5 .^{\mathrm{a}} 6\right.$. $^{\mathrm{a}} 8$. $\left.^{\mathrm{a}} 10 .^{\mathrm{a}}\right]$ viniendo del mal cierto al bien dudoso

- $\left[3 .^{\mathrm{a}} 5 .^{\mathrm{a}} 8 .^{\mathrm{a}} 10 .^{\mathrm{a}}\right]$ o $\left[3 .^{\mathrm{a}} 5 .^{\mathrm{a}} 6\right.$. $^{\mathrm{a}} 8$. $\left.^{\mathrm{a}} 10 .^{\mathrm{a}}\right]$ y que sabe cuán poco bien espera (Soneto XLII, 7)

- [1. $\left.{ }^{\mathrm{a}} 5 .^{\mathrm{a}} 7 .^{\mathrm{a}} 10 .^{\mathrm{a}}\right]$ tengo en humana forma abreviada

\subsubsection{Endecasílabos con acentuación en séptima}

Como ha señalado Jauralde, «entre los ritmos heroicos que no se han naturalizado en la métrica española resulta relativamente usual el de [2. ${ }^{a} 7$ a $^{\mathrm{a}}$ 10. $\left.{ }^{a}\right] \gg .{ }^{56}$ Ritmo del que se vale Hurtado de Mendoza en el siguiente verso:

- $\left[\left(2 .{ }^{\mathrm{a}}\right) 7 \cdot{ }^{\mathrm{a}} 10{ }^{\mathrm{a}}\right]^{57}$

Mas, ya que porque no mueran los vivos (Soneto XLIV,11)

Otro ejemplo con acento en séptima es [1. ${ }^{\mathrm{a}} 3$. $^{\mathrm{a}} 7 .^{\mathrm{a}} 10{ }^{\mathrm{a}}$ ] y que, siguiendo el manual de Jauralde, puede ser explicado como una variante del endecasílabo raro $\left[3 .^{\mathrm{a}} 7 \cdot^{\mathrm{a}} 10{ }^{\mathrm{a}}\right]$ :

- $\left[1 .^{\mathrm{a}} 3 .^{\mathrm{a}} 7 .^{\mathrm{a}} 10 .^{\mathrm{a}}\right]$

Tráeme ciego de verdad en verdad (Soneto XL, 5)

\footnotetext{
${ }^{56}$ El ritmo [2.7.10] recuerda a la mucho acentuación del octosílabo heroico difuso [2.7], ya que el acento esencial en séptima sílaba era propio del octosílabo español.

${ }^{57}$ Ejemplo estudiado y analizado en P. Jauralde Pou y otros, op. cit., p. 197.
} 


\subsubsection{Endecasílabos con acentuación en octava}

Otra variedad desechada del heroico que se encuentra reflejada en la poesía clásica española es $\left[2 .^{a} 8 .^{a} 10{ }^{a}\right]$, ritmo que no sólo utiliza Hurtado de Mendoza sino también Garcilaso, como recogió Navarro Tomás: ${ }^{58}$

En lágrimas como el lluvioso viento

(Garcilaso, Elegía I, “Al Duque d'alba en la

Muerte de Don Bernardino de Toledo", 23)

el fruto que con el sudor sembramos

(Garcilaso, Elegía II, “A Boscán”, 9)

En Diego Hurtado de Mendoza se encuentra esta acentuación en el verso:

- $\left[2 .^{\mathrm{a}} 8 .^{\mathrm{a}} 10 .^{\mathrm{a}}\right]$

[de ti, ni para publicar] mis males (Soneto $L, 10)$

Otro de los ritmos poco usuales con acentuación en octava es [3. $\left.{ }^{\text {a }} .{ }^{a} 10 .{ }^{a}\right]$. Navarro Tomás también recoge un ejemplo con este ritmo en Garcilaso: ${ }^{59}$

Por testigo de cuanto os he encubierto

(Garcilaso, Canción II. Estrofa 3, 3)

Por su parte Hurtado de Mendoza utiliza la acentuación [3. $^{\text {a }}{ }^{\mathrm{a}} 10$. $^{\mathrm{a}}$ ] en el verso:

duraré y permaneceré deste arte (Soneto LVII, 11)

Hasta aquí hemos podido comprobar que, sin olvidar las antiguas resonancias del ritmo del arte cancioneril, Mendoza profundiza, con mayor o peor acierto, en el ritmo del endecasílabo. No obstante, en los sonetos de Hurtado de Mendoza se advierte también la asimilación del nuevo ritmo del endecasílabo. A continuación, mostramos cuáles han sido los versos en los que el poeta demuestra esa adaptación hacia el ritmo acentual marcado, durante en Renacimiento, para el endecasílabo.

\footnotetext{
${ }^{58}$ Ejemplo recogido de P. Jauralde Pou y otros, op. cit., p. 197.

${ }^{59}$ Ibidem. P. Jauralde Pou y otros, pp. 181-205.
} 


\subsection{Rasgos de adaptación al ritmo acentual del endecasílabo}

En diversos estudios métricos los investigadores coinciden en que el ritmo del endecasílabo persigue una clara intención expresiva, un tono; quizá por esa razón los endecasílabos "prefieren modalidades acentuales en [1. $\left.{ }^{a} 4 .^{a} 8 .^{a} 10 .^{a}\right]$, [4. ${ }^{a}$

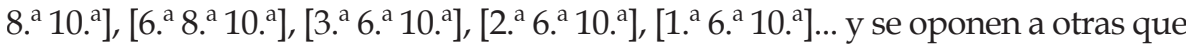



Como ya hemos visto el endecasílabo español a partir de Garcilaso distribuye sus acentos esenciales en proporciones constantes, es decir en primera o segunda, cuarta, sexta, octava y décima posición preferiblemente. En los ejemplos que analizamos a continuación, dividiremos los endecasílabos según la posición del primer acento rítmico: en la primera, segunda, tercera o cuarta sílaba, es decir, enfáticos, heroicos, melódicos, y sáficos, aunque sin olvidarnos de los endecasílabos vacíos.

No obstante - y como viene siendo habitual - comenzaremos por hacer un breve resumen histórico de los usos y preferencias del ritmo acentual en el endecasílabo. Dejando aparte algunas particularidades de la Edad Media, parece claro que el ritmo del endecasílabo mostró una predilección por los tipos: sáfico y el heroico. Al lado de estos ritmos, los otros tipos (enfático y melódico) se encontraron casi únicamente como versos de combinaciones ocasionales, y tuvieron, por tanto, importancia muy limitada. Por tanto, se pude decir que el endecasílabo español tiene un carácter rítmico más fijo que el modelo italiano. ${ }^{61}$

Es notable en Santillana la preferencia por el endecasílabo heroico, ocupando este ritmo la primera posición, después emplea más frecuentemente el melódico y por último el enfático. ${ }^{62}$ Sin embargo, es a partir del Renacimiento cuando desaparece, casi por completo, el ritmo dactílico del endecasílabo, y se produce, paulatinamente, un equilibrio entre el endecasílabo sáfico y heroico,

\footnotetext{
${ }^{60}$ R. Baehr, op. cit., p. 140-144.

${ }^{61}$ Compárese con R. Baehr, p. 140-144.

${ }^{62} \mathrm{Vid}$. La cita de lo que dice Fernando de Herrera al respecto de los versos "desmayados de Garcilaso" en J. Montero Reguera, op. cit., p. 617. Reproduzco parte de la cita: "Y oso afirmar, que ninguna mayor falta se puede hallar en el soneto que terminar los versos de este modo [con heroicos], porque aunque sean compuestos de letras sonantes, y de sílabas llenas casi todas, parecen de muy humilde estilo y simplicidad, no por flaqueza y desmayo de letras, sino por sola esta igual manera de paso, no apartando ningún verso; que yendo todo entero a acabarse en su fin, no puede tener cumplida, ni alteza, ni hermosura de estilo, si bien concurriesen todas las partes».
} 
de manera que ambos representan, con igual derecho, los tipos fundamentales del endecasílabo español. Aunque no será hasta la segunda mitad del XVI cuando el ritmo heroico alcance las proporciones de uso del endecasílabo sáfico, siendo los demás tipos (enfático y melódico) menos utilizados.

\subsubsection{Endecasílabos enfáticos}

Los endecasílabos enfáticos llevan sus acentos esenciales en primera y sexta sílaba, y son considerados como graves y sonoros por conferir al verso un ritmo intenso y muy marcado.

Como hemos visto, este ritmo era de uso poco frecuente tanto en el Marqués de Santillana como en los poetas del XVI, y como podemos observar, en Mendoza también es escasa la proporción de uso de este ritmo, ya que sólo lo emplea en quince versos.

\subsubsection{Endecasílabos heroicos}

Los sonetos de Mendoza tienen, como ya veremos, un ritmo predominantemente heroico. Ritmo, que sin duda, es muy apropiado para los momentos narrativos de los versos; y como tal, es más oportuna su utilización en los versos centrales donde se expone el caso.

Sin embargo, como ha destacado José Montero Reguera existe en el Soneto I de Garcilaso un uso poco adecuado del ritmo heroico en el terceto final: «y, curiosamente, el terceto final presenta un ritmo heroico, más propio de momentos narrativos, y por ello, acaso, inadecuado para el final del poema. De hecho, uno de los primeros comentaristas, Fernando de Herrera, llamó la atención sobre los finales "desmayados"de algunos sonetos de Garcilaso en los que usa precisamente el endecasílabo heroico». ${ }^{63}$

En Diego Hurtado de Mendoza también encontramos esa utilización del ritmo heroico, poco apropiado - según varias explicaciones - para el final de verso. Sin embargo en los siguientes versos, Mendoza al igual que Garcilaso, emplea ese ritmo marcadamente narrativo al final de verso:

\footnotetext{
${ }^{63}$ Baehr explica al respecto del verso sáfico: «el sáfico clásico "interger vitae scelerisque purus" se reprodujo en la baja latinidad como "integer vitae escelesrísque púrus" (óoo óo/ oo óo óo) conforme a la prosodia natural». Vid, R. Baehr, op. cit., p. 140-144.
} 
- $\left[2 .^{\mathrm{a}} 6 .^{\mathrm{a}} 10 .^{\mathrm{a}}\right]$ mas ésta para mí nunca se acaba (Soneto XXXIX, 14) las armas con que Aquiles os venció (Soneto XLV,14)

- $\left[2 .^{\mathrm{a}} 4 .^{\mathrm{a}} 6 .^{\mathrm{a}} 10 .^{\mathrm{a}}\right]$ tan ciega está de amor, que se $1[0]$ da (Soneto XLI, 14) que menos son tus males en ausencia (Soneto XXXIII, 14) el gran pompeo, muerto y no enterrado (Soneto XLVIII, 14) y el loco mar enmiende la sentencia (Soneto XLVI, 14)

- $\quad\left[2 .^{\mathrm{a}} 4 .^{\mathrm{a}} 6 .^{\mathrm{a}} 8 .^{\mathrm{a}} 10 .^{\mathrm{a}}\right]$ del tiempo bien llorado y mal perdido (Soneto LVIII, 14)

- $\left[2 .^{\mathrm{a}} 6 .^{\mathrm{a}} 8 .^{\mathrm{a}} 10 .^{\mathrm{a}}\right]$ que el rabo de una negra a media noche (Soneto XCVI, 14)

En otras ocasiones, aunque no ocupe, estrictamente, el último lugar del verso, sí se encuentra en el último terceto. En los demás versos de Hurtado de Mendoza, el ritmo heroico ocupa los versos centrales de sus sonetos, que es el lugar más adecuado para usar este ritmo de marcado carácter narrativo.

A continuación ofrecemos un breve repertorio con algunos versos en los que se ve ese uso del ritmo heroico, ya que así se puede tener una visión más adecuada, del que es el ritmo más empleado por Diego Hurtado de Mendoza en sus sonetos, ya que lo utiliza en 99 versos.

- Heroico puro [2. ${ }^{\mathrm{a}}$ 6. $\left.{ }^{\mathrm{a}} 10{ }^{\mathrm{a}}\right]$ : en años de pesar os me volvistes y cortas [si me] hubiese de quejar (Soneto XXXI, 4) y más el sobresalto lo desvela

- Heroico pleno [2. 4 a $^{\mathrm{a}} 6$. $\left.^{\mathrm{a}} 8 .^{\mathrm{a}} 10 .^{\mathrm{a}}\right]$ : en males crece amor y allí se cría ansí mi alma triste en sólo verte (Soneto XXXV, 2) esté sujeto a vos? Decid, lendroso

- Heroico corto [2. ${ }^{\mathrm{a}} 4$. $^{\mathrm{a}} 6$. $^{\mathrm{a}} 10$. $^{\mathrm{a}}$ ]: en mí faltó la orden de los hados en traje extraño y lengua desusada (Soneto XXXI, 5); ya yo sería contento en mi pasión

- Heroico largo [2. ${ }^{\mathrm{a}}$ 6. ${ }^{\mathrm{a}} 8$ 8 $^{\mathrm{a}} 10$. $\left.^{\mathrm{a}}\right]$ : que él, que parecía más ligero el hombre que doliente está de muerte (Soneto XLII, 1) 
- Heroico difuso [2. $\left.{ }^{\mathrm{a}} 4 .^{\mathrm{a}} 10 .{ }^{\mathrm{a}}\right]$

que nos encubres tanta hermosura (Soneto XLIV, 2)

- $\left[2 .^{\mathrm{a}} 3 .^{\mathrm{a}}\right.$ 6. $\left.{ }^{\mathrm{a}} 10{ }^{\mathrm{a}}\right]$ Variante extrarrítmica del endecasílabo heroico puro $\left[2 .^{\mathrm{a}} 6 .^{\mathrm{a}} 10 .^{\mathrm{a}}\right]$ razón es que los llore ahora doblados (Soneto XLVII, 8) pero [hay gran] diferencia verdadera (Soneto LII, 7) y mil veces al fin he deseado $\quad$ (Soneto LII, 4)

\subsubsection{Endecasílabos melódicos}

Estos endecasílabos tienen un ritmo suave y apacible, y son los más apropiados para crear un compás equilibrado y flexible en los versos de transición del soneto.

En los sonetos de Diego Hurtado de Mendoza este ritmo se extiende por 84 versos, y es, tras los endecasílabos heroicos y sáficos, el ritmo más habitual. Tal y como podemos comprobar en este seleccionado repertorio:

- Melódico puro $\left[3 .^{\mathrm{a}} 6{ }^{\mathrm{a}}{ }^{\mathrm{a}} 10{ }^{\mathrm{a}}\right]$ que podréis en el tiempo que vivistes (Soneto XXXI, 7) $\mathrm{y}$ en la causa del mal se le convierte (Soneto XLII, 4)

- Melódico pleno [1. ${ }^{\mathrm{a}} 3{ }^{\mathrm{a}} 6{ }^{\mathrm{a}}{ }^{\mathrm{a}}$. $\left.{ }^{\mathrm{a}}{ }^{10}{ }^{\mathrm{a}}\right]$ vuelve el cielo y el tiempo huye y calla (Soneto XXXIII, 1) halla daño si busca haber reposo (Soneto XLII, 6)

- Melódico largo [3. $\left.{ }^{\mathrm{a}} 6 .^{\mathrm{a}} 8 .^{\mathrm{a}} 10{ }^{\mathrm{a}}\right]$ mas en mí este remedio no ha lugar inmortal hermosura y voz divina

- Melódico corto $\left[1 .^{\mathrm{a}} 3 .^{\mathrm{a}} 6 .^{\mathrm{a}} 10 .^{\mathrm{a}}\right]$ largas son de sufrir cuanto a su dueño (Soneto XXXI, 9) que era gloria y no pena mi pasión （Soneto XXXVII, 4)

\subsubsection{Endecasílabos sáficos}

La inexplicable preferencia por este ritmo en el endecasílabo castellano del siglo XV y XVI hizo que varios investigadores - sin duda, el más destacado Navarro Tomás - intentasen averiguar el origen de este ritmo. 
Baehr, por su parte, considera que este endecasílabo «intenta imitar al pretendido verso sáfico clásico», ${ }^{64}$ que por su ritmo es, en realidad, el latino medieval. Navarro Tomás, sin embargo, «ve en el sáfico clásico la base del decasílabo románico con acentos en $4 .{ }^{\mathrm{a}}$ y $8 .{ }^{\mathrm{a}}{ }{ }^{65}$

Por otra parte, hay que destacar que el endecasílabo sáfico, por tener su primer apoyo en $4 .{ }^{\mathrm{a}}$, es un ritmo lento y suave, siendo, además, el ritmo más adecuado para la exaltación lírica.

En los versos de Mendoza, el ritmo sáfico se muestra en 52 versos, en los que se alterna los versos acentuados en $\left[4 .^{a}{ }^{\mathrm{a}} .^{\mathrm{a}} 10{ }^{\mathrm{a}}\right]$ con los $\left[4 .^{\mathrm{a}} 8 .^{\mathrm{a}} 10 .^{\mathrm{a}}\right]$, aunque, si bien, predominan los primeros.

\subsubsection{Endecasílabos vacíos}

Son endecasílabos vacíos todos aquellos que no presentan acento esencial antes de la $6 .^{a}$ sílaba, y que su arranque produce una sensación de falta de apoyo.

Sin embargo, como explicábamos anteriormente, el endecasílabo no suele aceptar esta secuencia [oo oo oó ooo óo] y sería conveniente añadir algún acento de apoyo, teniendo en cuenta que en ocasiones esos acentos secundarios pueden ser muy forzados y distorsionar la melodía:

- Vacío puro [6. $\left.{ }^{\mathrm{a}} 100^{\mathrm{a}}\right]$ en arrepentimiento y desengaño $\mathrm{y}$ todo inconveniente muy liviano como con los del alma y del deseo y porque, con mi muerte, mi fortuna y si en la matadura de una haca

(Soneto XXXVII, 13)

(Soneto XXXIX, 4)

(Soneto $L, 14$ )

(Soneto LVI, 12)

(Soneto XCVI, 5)

Otros ejemplos de endecasílabos vacíos serían los que, manteniendo la estructura esencial $\left[6{ }^{a} 10{ }^{a}\right]$, añaden un acento inmediato en séptima sílaba:

$$
\text { en desesperación busco ventura (Soneto XLII, 14) }
$$

Así pues, los resultados de este análisis acentual confirman las principales tendencias del estilo de Hurtado de Mendoza. Por una parte, hemos comprobado cómo sus sonetos repiten el mismo ritmo acentual

\footnotetext{
${ }^{64}$ T. Navarro Tomás, op. cit., p. 175.

${ }^{65}$ M. Fubini, «El soneto», Métrica y poesía, Barcelona, Planeta, 1970, p. 185.
} 
(dactílico y sáfico difuso) que el Marqués de Santillana; y que define ese estilo tan característico de Mendoza anclado en la lírica cancioneril. Por otra, nos encontramos con que las diferencias con los poetas del XVI son evidentes, sobre todo, en ese uso todavía perceptible de la acentuación en $5 .^{a}, 7 .^{a}$ y $8 .^{a}$ (prácticamente inexistente en los sonetos de principios del XVI). Del mismo modo, hay que decir que se aprecian signos que confirman ese intento de Diego Hurtado de Mendoza por asimilar el ritmo del endecasílabo, pues se observa un uso destacado, y de extensión muy similar al utilizado por los poetas de su generación, del endecasílabo heroico y melódico.

\section{Rimas en los sonetos de Hurtado de Mendoza.}

Por su brevedad el soneto fue también un «medio de experimentación». ${ }^{66}$ Existió en esta estrofa, desde su origen, un campo experimental para extravagancias y juegos, para rimar palabras equívocas, para realizar rimas internas o para intentar esquemas de rimas complicados.

Como veremos en este apartado, Diego Hurtado de Mendoza también consideró el soneto como una estrofa propicia para el juego y para la experimentación con nuevas combinaciones de rimas. Veamos pues, cómo y qué rimas utiliza Mendoza, cómo va complicándolas cada vez más, creemos que, para impresionar por su originalidad a todo aquel que se acerca a su poesía. Todo ello, hasta llegar a una complejidad que analizaremos en dos apartados: rimas y esquemas de rimas.

\subsection{Rimas}

Hay varias definiciones de rima aunque todas coinciden en un rasgo común, el de identificarla «como un sonido que se repite a intervalos regulares dentro de un poema» ${ }^{67}$ normalmente - aunque no exclusivamente - a final de verso.

Una definición tan sencilla de rima nos puede llevar a pensar en un uso muy simple pero, como se mostrará más adelante, en el caso de Diego Hurtado de Mendoza las rimas recibirán todo tipo de variaciones y combinaciones insólitas.

${ }^{66}$ P. Jauralde Pou, y otros, op. cit., p. 99.

${ }^{67}$ P. Jauralde Pou, y otros, op. cit., p. 100. 
No obstante, esta definición de rima es limitada si lo que pretendemos es dar cabida a las características particulares de Hurtado de Mendoza. Por eso, deberemos tener presente a la hora de estudiar este fenómeno la indisolubilidad entre forma y contenido en la rima. Más concretamente, en palabras de Pablo Jauralde, «la función de la rima consiste, inicialmente, en provocar un juego sonoro con el significante de la lengua, que así acentúa sus valores estéticos pero sin olvidar, como señala Jakobson, que: "simplificación errónea es el tratar la rima tan solo desde el punto de vista del sonido, puesto que incluye, por necesidad, la relación morfológica, genérica, semántica, etc. Que hay entre las unidades de la rima" $\gg{ }^{68}$

Por eso, lo que intentaremos en este apartado será analizar la rima desde un punto de vista fonológico pero haciendo, en algún caso, extensible la explicación a la semántica.

En cuanto a la rima, debemos decir que según su disposición en el verso puede ser rima final o interna. Por esta razón y para un mejor análisis de las rimas de Mendoza los dividiremos en estos dos epígrafes.

\subsubsection{Clases de rimas finales}

La rima es «un hecho de eufonía pero también es un fenómeno rítmico porque se confecciona a la espera de un repetición». ${ }^{69}$ Por eso, «si se repite un sonido exclusivamente vocálico a partir del último acento del verso, la rima final será asonante, y si se repite un sonido consonántico y vocálico, la rima será consonántica». ${ }^{70}$

Desde los orígenes del soneto fue más frecuente la utilización de la rima consonántica porque es la forma más común y normal de todas, conforme al predominio de las terminaciones consonánticas paroxítonas en español. Sin embargo, en los sonetos Hurtado de Mendoza es muy llamativo ese uso tan frecuente de la rima asonante, ya que nos encontramos con un amplio repertorio de rimas asonantes, muy superior al uso de otros poetas.

\section{- Rima asonante}

Como ya habíamos dicho, en los casos en los que después del último acento sólo se repiten sonidos vocálicos se puede hablar de rima asonante.

\footnotetext{
${ }^{68}$ Definición que tomamos de Baehr. R., Baehr, op. cit., pp. 61-77.

${ }^{69}$ Ibidem. P. Jauralde Pou, p. 99.

${ }^{70}$ R. Baehr, op. cit., p. 27.
} 
Según el grado de igualdad entre las rimas asonantes, podremos distinguir entre rimas asonantes perfectas y rimas asonantes imperfectas.

Las rimas asonantes perfectas exigen la igualdad y similitud total de todas las vocales que riman. En los sonetos de Hurtado de Mendoza las rimas de este tipo no son muy elaboradas, ya que todas son, mayormente, desinencias verbales en: -ía, - ea, - eo.

Los casos más obvios de rimas compuestas a partir de desinencias verbales son las terminadas en -eo y - ea. Incluso muchas veces esas rimas pertenecen al mismo verbo variando únicamente el tiempo verbal. Como en los casos de «deseo»y «desea», «veo»y «vea»:

tal, que huye sentir lo que desea; su pensamiento a otros lisonjea,

(Soneto XLI, 6-7)

tornare a tu poder, que en él me vea. y, porque mi jurar más firme sea, quien causare mi mal no me lo crea.

(Soneto LIV, 10, 12, 14)

no hay paciencia tan baja que no sea quien quiebra el orinal donde se mea.

(Soneto CXIX, 10,12)

En las terminaciones en -eo, existen, además, dos ejemplos en los que se repite exactamente la misma forma verbal, rimando al mismo tiempo entre ellas:

ni por verte más veces que te veo;

como con los del alma y del deseo.

(Soneto L, 11, 14)

Tiempo vi yo que Amor puso un deseo

Tiempo vi yo, que ahora no lo veo

(Soneto XXXVII, 1,3)

Otro caso de asonancia perfecta es el que se produce con la terminación -ía, rima que llega a ser monótona por proceder mayormente de la misma desinencia verbal, y también por ser la rima asonante más utilizada en los sonetos por Mendoza. Veamos algunos ejemplos de esta rima: 
Vi como sobre todas parecía de la parte mayor que en si tenía

(Soneto XXXIV, V 9, 14)

en males crece amor y allí se cría de sus penas costumbre y compañía

(Soneto XXXV, 2, 4)

por no tomar el descanso que solía.

Y, como no lo vi donde lo vía. cuando por más contento me tenía, pues que ya le perdí por culpa mía

(Soneto XLVII, 2 -3, 6-7)

Además de éstas existe otra rima asonante perfecta, pero que por ser un monosílabo la hemos analizado por separado. Según Baehr las rimas asonantes agudas pueden considerarse como asonantes, sin embargo se las considera como ambivalentes ${ }^{71}$ porque pueden ser empleadas como rimas asonantes o consonantes.

Y si algún placer me trae, con él me va tan ciego está de amor, que se lo da

(Soneto XL, 11, 14)

Por otra parte, existe también un ejemplo de rima asonante imperfecta, que es aquella en la que no existe una coincidencia exacta entre las vocales que riman. Pero que en este caso sirve para reforzar la antítesis, la pugna de ideas, que se pone de relieve al contrastar dos formas verbales que pertenecen a dos tiempos verbales tan diferentes: futuro y pasado.

cuándo será aquel día que estaré juzga lo que ha de ser por lo que fue

(Soneto XLV, 10, 13)

Este fenómeno es muy abundante en la lírica del $\mathrm{XV}$, y por lo visto, también en la poesía del XVI. Lapesa ${ }^{72}$ lo explica de la siguiente forma:

\footnotetext{
${ }^{71}$ Vid. R. Lapesa, 1985, op. cit., p. 27.

${ }^{72}$ Vid. Ortografía de la lengua española, Madrid, Real Academia Española, 1999, p. 18.
} 
[...] Esteejemploabunda muchoen el sigloXV castellano.Su manifestación más conocida es la célebre "razón de la sinrazón" que contribuyó a secar el celebro de Don Quijote. Pero que en los siglo XV y XVI alcanzaron una boga extraordinaria.

\section{- Rima consonante}

De igual modo que las rimas anteriores, clasificaremos las rimas consonantes. Principalmente por su grado de igualación, analizándolas como rimas consonánticas perfectas o imperfectas.

La consonancia perfecta, al igual que la asonancia perfecta, exige la exacta coincidencia fonética, aunque no necesariamente gráfica, de todos los sonidos de la rima.

Así nos podemos encontrar con rimas consonánticas sin igualdad en la grafía pero que reproducen el mismo sonido, dado que la $g$ se presenta como un «fonema velar sordo ante las vocales e, i», ${ }^{73}$ como en el caso que aquí señalamos:

hállole ser de mí tan extranjero que él, que parecía mas ligero

(Soneto XXXIX, 4-5)

Siguiendo lo que parece ser una característica de la época, existe un ejemplo de palabras que tienen un representación gráfica y fonética muy parecida. Denominadas por Baehr como «rima de palabras parónimas».Como en este ejemplo en el que sólo varía una vocal:

que no tengo tan dura la costilla

cual nunca dio a mujer hombre en Castilla

(Soneto XCV, 10, 14)

Como forma especial de la consonante perfecta hay que mencionar una especie de rima intensa, en la que además de la coincidencia de los sonidos posteriores al acento, se exige la igualdad en uno o más sonidos anteriores. Sin duda, uno de los rasgos más característico y representativo de las rimas de Hurtado de Mendoza. Es el caso de:

\footnotetext{
${ }^{73}$ Estas rimas ya han sido explicadas y analizadas en el Epígrafe 1 de este artículo. Compárese con lo dicho en las páginas 5 y 6 de este trabajo.
} 


$$
\begin{aligned}
& \text { que era gloria y no pena mi pasión }{ }^{74} \\
& \text { tiempo vi yo que por una ocasión } \\
& \text { (Soneto XXXVII, 4-5) }
\end{aligned}
$$

y porque con mi muerte, mi fortuna y a mí quite el vivir que me importuna

(Soneto LVI, 12, 14)

Otra rima peculiar y muy característica de Diego Hurtado de Mendoza es la rima idéntica o unisonante, en la que se repite para rimar al final de verso la palabra entera:

$$
\begin{aligned}
& \text { y nace su holganza de locura } \\
& \text { que no hay en mi dolencia cura } \\
& \text { como el que viendo vive en noche oscura }
\end{aligned}
$$$$
\text { (Soneto XXXVI, 2, 4, 8) }
$$

cualquier tiempo me estorba la jornada que en mí siempre es mayor lo que no es nada

$$
\text { (Soneto XXXVI, 11, 14) }
$$

Y, si con él me veo mano a mano me parece pesado e inhumano

$$
\text { (Soneto XXXIX, 5, 8) }
$$

y esparcidas hojas por el suelo aunque en miralla no falta consuelo

$$
\text { (Soneto XLIV, 4, 8) }
$$

y del miedo y vileza de cartago mas quédame un consuelo en lo que hago

(Soneto XLIX, 11-12)

y por tan gran razón seréis servidas que, si mi vida dura por mil vidas

$$
\text { (Soneto LV, 6-7) }
$$

Es evidente que en algunos de estos ejemplos se vuelve a mostrar la rima como un instrumento para reforzar la antítesis. En estos ejemplos de rima

\footnotetext{
${ }^{74}$ R. Lapesa, 1985, op.cit , p. 19.
} 
idéntica se pone de relieve por contraste la pugna de ideas, de sentimientos, o de burla:

honesto en un honesto corazón

Señora, en tu presencia, la razón

(Soneto XXXXVII, 2, 7)

a esta fiera crüel amando sigue

ella huye de todos y persigue

(Soneto XXXVIII, 2-3)

que le traiga a las manos de cupido

y en la parte contraria un escupido

(Soneto XCVIII, 11, 14)

Por otra parte, nos encontramos con casos de consonancia imperfecta en los que Mendoza hace rimar los diptongos -ié, -ué, con la vocal -é:

hace que no se sienta ni se duela

y morir cuando menos se recela

(Soneto XXXII, 4, 6)

y esparcidas las hojas por el suelo

si la escondes, movida con buen celo

(Soneto XLIV, 4-5)

sin recelar humano impedimento

y castigaron solo el sufrimiento

(Soneto XLVII, 10, 14)

que nos traes embaucados tierra y cielo

cuántas veces te ha $\mathrm{n}$ visto andar en celo

(Soneto XCV, 2-3)

Dentro de la consonancia imperfecta existen casos de rimas con consonancia simulada, que son las rimas en la que se repite casi por completo la rima a excepción de una que casi siempre la primera consonante:

Largas son de sufrir cuanto a su dueño

que la razón me huye como sueño

(Soneto XXXI, 9, 12) 
si alguna breve gloria me fue dada la vida congojosa toda es nada

$$
\text { (Soneto XXXII, 10, 13) }
$$

Vuelve el cielo, y el tiempo huye y calla tanto más cuanto más lejos te halla

(Soneto XXXIII, 1, 4)

Aun por haceros Grecia mayor mengua y entregando a la vil y flaca lengua

(Soneto XLV, 10, 13)

por la orilla del río Nilo, le convino compaña que a los reyes de contino

(Soneto XLVIII, 3, 6)

puñada a mojicón, aunque más digas

Encima de mis ojos lluevan higas

(Soneto XCIX, 2, 5)

El caso que exponemos a continuación, corresponde a una rima muy utilizada por los poetas del XVI, ya que incluso Garcilaso hace uso de ella en varias ocasiones. Lapesa ${ }^{75}$ la estudia en la canción I de Garcilaso:

Como en mí vuestros males son de otra arte,

Duénleme en más sensible y tierna parte

(Garcilaso, Canción I, 25-26)

En Diego Hurtado de Mendoza encontramos la misma rima en:

duraré y permaneceré deste arte

que tu vista figura en toda parte

(Soneto LVII, 11, 14)

\subsubsection{Rima interna}

La rima interna consiste en rimar el final del verso con el final del primer hemistiquio del verso siguiente, y se cree que fue introducida cuando las formas métricas italianas dominan la poesía española del XVI.

\footnotetext{
${ }^{75}$ M. Fubini, op. cit., p. 200.
} 
Sin embargo, si seguimos los estudios realizados por Mario Fubini, comprobaremos que ya en el soneto primitivo del duecento italiano existía otra clase de rima interna. En estos primeros sonetos italianos se repetía, de forma casi imperceptible, un artificio de la poesía provenzal que consistía en unir las estancias entre sí, repitiendo al principio de la estancia siguiente la última palabra de la anterior. ${ }^{76}$ Fubini, ejemplifica este artificio con los siguientes versos de Dante:

da cielo in terra a miracol mostrare.

Mostrasi sí piacente a chi la mira ${ }^{77}$

En los sonetos de Hurtado de Mendoza, también hemos encontrado ejemplos donde se muestra ese artificio de ascendencia italiana:

$$
\begin{aligned}
& \text { Vuelve el cielo, y el tiempo huye y calla } \\
& \text { y callando despierta tu tardanza }
\end{aligned}
$$

(Soneto XXXIII, 1-2)

que no fue poco ver hombre mortal inmortal hermosura y voz divina,

(Soneto XXXIV, 10-11)

Sin embargo, existe aún otra clase de rima interna, característicamente castellana, y que tiene su precedente más inmediato en la lírica de cancionero. Como señala Lapesa, la poesía de los cancioneros castellanos no dejó de influir sobre los «líricos del periodo áureo». En palabras de Lapesa: «Si hay un petrarquismo soterrado en los octosílabos y versos de arte mayor del siglo $\mathrm{XV}$, no faltan en la centuria siguiente vestigios del cancionero tradicional disfrazados bajo formas italianas». ${ }^{78}$

Este fenómeno, que podríamos llamar poliptoton o derivación, era muy del gusto de los poetas castellanos, y constituye otro modo de buscar la rima en la poesía de cancioneros. Por medio de la reiteración conceptista, de

\footnotetext{
${ }^{76}$ Recogido de Fubini, ibidem, p. 200.

${ }^{77}$ R. Lapesa, 1985, op. cit., p. 213-215.

${ }^{78}$ Mario Fubini considera como ciertas dos teorías sobre el origen del soneto. La primera es la que acerca el soneto a un origen popular, basado en la forma métrica del estrambote siciliano; la segunda afirma que el esquema del soneto corresponde al de la canción. Ambas teorías pueden ser compatibles, sin embargo hay razones muy válidas que apoyan la hipótesis de la derivación del soneto del estrambote. Vid., M. Fubini, op. cit., pp. 176-178.
} 
juegos de palabras y de reiteración verbal se logra un efecto de concentración obsesiva, en el que el ingenio está al servicio de la intensificación expresiva.

En líneas generales, esa reiteración y juegos de palabras que se muestran en los versos de Hurtado de Mendoza se erigen sobre las bases de la lírica cancioneril, pero, como ha estudiado Rafael Lapesa, este no es un caso originario de Mendoza, ya que también es un recurso muy empleado por Garcilaso. A continuación exponemos algunos ejemplos que se producen en los sonetos de Hurtado de Mendoza:

gasto en males la vida y amor crece

en males crece amor y allí se cría

(Soneto XXXV,1-2)

Siguió mi voluntad mi corazón

más él nunca siguió mi voluntad

(Soneto XL, 3-4)

que con falsa esperanza de ocasión, me sostenga siquiera en vanidad.

Tanto sería de vana esta esperanza, que no podría caber en mí sentido ni en consejo de amor ni en vanagloria.

(Soneto XL, 7-11)

¡Si fuese muerto ya mi pensamiento y pasase mi vida así durmiendo aueño de eterno olvido, no sintiendo pena, (ni) gloria, desanso ni tormento. Triste vida es tener el sentimiento tal, que huye sentir lo que desea; su pensamiento a otros lisonjea, yo enemigo de mí siempre lo siento.

(Soneto XLI, 1-8)

\subsubsection{Otras clases de rimas: carácter reiterativo y rítmico de la rima.}

Bajo este epígrafe aglutinamos todas las rimas que no son demasiado esperadas por apoyarse en las relaciones gramaticales y semánticas de forma muy obvia. Estas rimas son las que caracterizan y particularizan las rimas de Mendoza, ya que los finales de sus versos están plagados de estas rimas categoriales. 
- Rimar una palabra con su compuesto:

Y cuán despacio destemplados tiempos

Triste la larga en breves pasatiempos

(Soneto LVIII, 10-13)

- Rimar la misma palabra

ansí mi alma triste en solo verte

del duro conocerte al duro verte

(Soneto XLII, 4, 8)

- Rimar dos palabras fonéticamente idénticas pero con significados distintos

Que el uso de vivir siempre en cuidado $\mathrm{y}$ riése la muerte del cuidado

(Soneto XXXII, 3, 14)

- Rima apagada que por su frecuente aparición constituye una rima pobre y débil.

$$
\begin{aligned}
& \text { ni en consejo de amor ni en vanagloria } \\
& \text { que finja yo que estoy en tu memoria }
\end{aligned}
$$

(Soneto XL, 11-12)

- Otras manifestaciones de eufonía del verso, como es la armonía vocálica, que consiste en la repetición o simetría de la disposición de las vocales del verso, especialmente las que llevan el acento rítmico.

$$
\text { en traje extraño y lengua desusada [á á é á] }
$$$$
\text { dando y quitando leyes a su grado [á á é á] }
$$

(Soneto XXXIV, 7-8)

\subsection{Esquemas de la rima}

Para comprender el origen de las divergencias existentes entre el esquema de rimas utilizado por Hurtado de Mendoza y el empleado por los poetas que forman su grupo generacional, debemos delimitar los factores que determinaron ese cambio que se hace visible en el uso tan novedoso e insólito en la combinación de rimas. 
Obviando algunas explicaciones, creemos que innecesarias, sobre sus compañeros de generación trataremos de esbozar cuáles han sido las causas que pudieron propiciar esta diferencia en Hurtado de Mendoza. Es probable que entre esas diferencias encontremos rasgos que acerquen a nuestro poeta a la lírica de cancionero (arcaísmos) y otros rasgos que, por el contrario, manifestarán ese espíritu experimentador e innovador del que habíamos hablado al comienzo de este trabajo.

No obstante, no debemos delimitar la explicación del origen del fenómeno a los poetas de esa primera generación petrarquista, ni al primer testimonio de soneto en la literatura castellana (Marqués de Santillana) pues éste es un fenómeno que tiene su explicación y precedente en los sonetos italianos del duecento (los sonetos predantescos).

Llegado a este punto conviene hacer un breve apunte histórico sobre el origen del soneto. ${ }^{79}$ Comenzaremos por decir que el soneto primitivo italiano se forma, casi con total seguridad, a partir de que se repite en una breve composición la forma métrica del estranbote siciliano, formado por ocho versos de rima alterna. Como señala Mario Fubini: ${ }^{80}$

[...]Se observó que los primeros sonetos tenían en los cuartetos el esquema $\mathrm{ABAB}$, mientras que después predomina la forma $\mathrm{ABBA}$.. Las rimas alternas de los primeros cuartetos impedían, por lo tanto, distinguir claramente los dos cuartetos, por lo que había una serie de dísticos como en una octava siciliana. Los tercetos parecieron en cambio un estrambote, sin dos versos, con la forma CDCDCD. El soneto, en su origen, habría derivado de la fusión de los estrambotes o rispetti sicilianos.

En un segundo momento, cuando el soneto pasa a las demás regiones de Italia varios poetas imitan su forma métrica y el soneto se consolida en la forma ABBA. En los tercetos la rima originaria CDC DCD es complementada con otras, entre ellas la preferida CDE CDE. ${ }^{81}$

Todas estas afirmaciones sobre el origen del soneto italiano son ejemplificadas por Mario Fubini con un soneto de Jacopo da Lentini, ${ }^{82}$ en el

\footnotetext{
${ }^{79}$ Ibidem, M. Fubini, p. 177-178.

${ }^{80} \mathrm{Ibidem}, \mathrm{M}$. Fubini, p. 179.

${ }^{81}$ Para este soneto consúltese B. Croce, «Un sonetto di Jacopo da Lentini», Poesia antica e moderna, Bari, Laterza, 1941, pp. 48-50. También en : M. Fubini, op. cit., p. 180.

${ }^{82}$ Traducción del soneto: "Me he propuesto servir a Dios, para así poder ir al paraíso, al lugar santo donde he oído decir hay siempre alegría y risas. Pero sin mi amada no quisiera ir, la de
} 
cual se observa esa primera etapa del soneto en la que la rima era cruzada y no existía diferenciación entre los cuartetos:

Io m’ag(g)io posto in care a Dio servire, $\mathbf{A}$ com 'io potesse gire im paradiso, B al santo loco c'ag(g)io audito dire, A u'si mantien sollazzo, gioco e riso. B Sanza mia donna non vi voria gire, $\mathbf{A}$ quella c'ha la blonda testa e claro viso, B ché sanza lei non poteria gaudere, $\mathbf{A}$ estando da la mia donna diviso. B

Ma non lo dico a tale intendimento, $\mathrm{C}$ Perch'io peccato ci vollesse fare; D Se non veder lo suo bel portamento $C$ E lo bel viso e' 1 morbido sguardare: $\mathbf{D}$ mi teria in gran consolamento $\mathbf{C}$ Veg(g)endo la mia donna in ghiora stare ${ }^{83} \mathbf{D}$

Por otra parte y ya en la literatura castellana, el soneto clásico castellano se ha conservado casi inalterado desde Petrarca, conservándose en la literatura como estrofa de catorce versos endecasílabos dispuestos en dos cuartetos y dos tercetos de ocho y seis versos respectivamente. Como ya hemos visto, históricamente los cuartetos podían tener dos combinaciones de rimas, cruzada $\mathrm{ABAB} A B A B$ y abrazada $\mathrm{ABBA} A B B A$; mientras que el orden de las rimas de los tercetos era más libre y podía realizarse en combinaciones con dos rimas: $\mathrm{CDC} \mathrm{DCD}, \mathrm{CDC} C \mathrm{CDC}, \mathrm{CDD} \mathrm{DCC}$; o con tres rimas: $\mathrm{CDE} \mathrm{CDE}$, CDE DCE, CDE DEC, CDE EDC. ${ }^{84}$

Pero dejando a un lado la teoría, vayamos a interpretar cómo se manifiesta este esquema de rimas en la práctica en los poetas que utilizan como estrofa el soneto. Explicación que comenzaremos con el Marqués de Santillana y terminaremos con los poetas que integran el grupo poético de principios del siglo XVI. Una vez más será necesario remontarnos hasta la

rubios cabellos y rostro bello, porque sin ella no podría gozar, estando lejos de ella. Pero no digo esto con intención de cometer pecado; sólo quiero ver su porte elegante, su bello rostro y sus suave mirada: pues esto sería para mí gran consuelo, viendo que mi amada está en la gloria". Ibidem, M. Fubini, p. 180.

${ }^{83}$ R. Baehr, op. cit., pp. 385-391.

${ }^{84}$ R. Baehr, op. cit., pp. 385-391. 
Edad Media dado que es a mediados del siglo XV donde se encuentra el testimonio más temprano de soneto castellano.

Santillana se decanta por la rima cruzada $\mathrm{ABAB} A B A B$ en los cuartetos de sus sonetos; la explicación estriba, según Baehr, en que la rima abrazada era muy parecida a la combinación de rimas que se utilizaba en la copla de arte mayor. Por lo tanto, para evitar la confusión entre ambas estrofas se decantó por la cruzada $\mathrm{ABAB} A B A B .85$

Sin embargo y a pesar de que la rima cruzada tenía su origen en el patrón del soneto italiano primitivo, no se naturalizó en los sonetos de principios del siglo XVI. La rima cruzada sólo se usó en la primera época del soneto español siendo posteriormente rechazada por Garcilaso y los restantes poetas de la primera generación petrarquista dado que consideraban esa disposición de rimas $(\mathrm{AB} A \mathrm{~B} \mathrm{ABAB})$ como un rasgo arcaizante.

En líneas generales, todos los poetas de principios del XVI mantuvieron cierto equilibrio entre tradición medieval y las nuevas corrientes métricas llegadas de Italia, aunque siempre orientando su poesía hacia la estética y mesura del verso, donde ritmo estaba asociado emotividad que pretendían transmitir. Ejemplos de esa tendencia son Garcilaso, Boscán, Cetina y Acuña. Sin embargo, - una vez más - Mendoza se queda al margen de ese proceso que inician sus compañeros.

Pero, dejando a un lado esta cuestión, lo que aquí nos interesa determinar es si nos hallamos ante un fenómeno excluyente - propio de Hurtado de Mendoza - o si, por el contrario, podría ser un fenómeno compartido por otros poetas de su generación. Para ello iremos explicando y comparando los esquemas métricos utilizados por Mendoza con los que utilizan el Marqués de Santillana y Garcilaso.

Comenzaremos por presentar el esquema completo de todas las combinaciones de rimas que utiliza Mendoza en sus treinta y tres sonetos. El esquema ha sido elaborado por Luis Díaz Larios y Olga Gete Carpio: 86
1. ABBA: ABBA a) CDC: DCD: XXXVIII, XLVII, LIII, LIV, LV, LVI.
c) CDE: CDE: XXIII, LVIII, XCVII, XCVIII.
d) CDE: DCE: XXXIX.

\footnotetext{
${ }^{85}$ D. Hurtado de Mendoza, 1990, op. cit., p. 37.

${ }^{86}$ I. López de Mendoza, op. cit., p. 156-157.
} 
e) CDE: EDC: XL, XLII.

g) CDE: DEC: XLIX, XCVI.

f) CDE: CED: LII.

2. ABBA: BAAB b) CDD: CCD: XXXI.

d) CDE: DCE: XCIX.

3. ABAB: ABAB a) CDC: DCD: XLVI.

c) CDE: CDE: XXXII, XLV, L, LVI.

e) CDE: EDC: XXXIV, XXXV, LI.

4. ABAB: BABA a) CDC: DCD: XCV

e) CDE: EDC: XLIII, XLVIII, XLIX.

5. ABAB: BAAB a) CDC: DCD: XXXVI

6. ABBA: ACCA h) DEF: DEF: XLI

7. ABAB: BCBC h) DEF: DEF: XXXVII

El esquema que anteriormente hemos reproducido nos deja observar, por una parte, el predominio en los cuartetos de paradigmas insólitos para los poetas coetáneos a Diego Hurtado de Mendoza. Existe una clara tendencia a romper el orden de las rimas, prefiriendo las rimas cruzadas $A B A B A B A B$ como era frecuente, como ya hemos visto, en los primeros sonetistas italianos del duecento y en el Marqués de Santillana.

Como habíamos dicho Santillana prefería la rima (ABAB $A B A B)$ para diferenciarla de la rima utilizada en la copla de arte mayor castellana; sin embargo, hay que considerar de manera muy distinta el caso de Hurtado de Mendoza.

Como se muestra en el esquema anterior, Mendoza utiliza la forma cruzada $\mathrm{ABAB} A B A B$ en ocho de sus sonetos. Sin embargo, son diferentes las motivaciones que llevaron a Hurtado de Mendoza a reproducir, en cierta manera, el esquema de rimas de Santillana. Según Baehr, en Diego Hurtado de Mendoza se trata de «un intento por amoldar la forma fija de la cuarteta italiana a las formas autóctonas mediante variaciones en la disposición de las rimas».

Intentaremos demostrar con dos ejemplos la afinidad existente entre la combinación de rimas empleada por el Marqués de Santillana en Los sonetos fechos al itálico modo y la utilizada por Hurtado de Mendoza en sus sonetos. 
Esa «afinidad» se hace visible en la utilización de un esquema de rimas muy peculiar con tres rimas en los cuartetos.

En los sonetos que ahora exponemos de Santillana y de Hurtado de Mendoza destaca un uso de rimas con tres consonancias en los cuartetos, en vez de las dos que eran costumbre tanto en los sonetistas italianos como en los castellanos.

Obsérvese la igualdad y rareza del esquema de rimas empleado por ambos poetas: ABBA ACCA DEF DEF.

\section{Soneto X}

Fiera Castino con aguda lança $\mathbf{A}$ la temerosa gente pompeana; $\mathbf{B}$ el cometiente la mas veces gana, $\mathbf{B}$ al victorioso nuze la tardança. $\mathbf{A}$

Razón nos mueve, e cierta esperança $\mathbf{A}$ es el alférez de vuestra vandera, $\mathbf{C}$ e justicia patrona e delantera, $\mathbf{C}$ e nos conduce con grand ordenança. A

Recuérderos la vida que bivides, $\mathbf{D}$ la qual yo llamo imagen de muerte, $\mathbf{E}$ e tantas menguas séanuos delante; $\mathbf{F}$

Pensad las causas por que las sufrides, D ca en vuestra espada es de buena suerte $\mathbf{E}$ e los honores del carro triunfante. $\mathbf{F}$

(Soneto $X^{87}$ Marqués de Santillana)

\section{Soneto XL}

¡Si fuese muerto ya mi pensamiento $\mathbf{A}$ y pasase mi vida así durmiendo $\mathbf{B}$ sueño de eterno olvido, no sintiendo $\mathbf{B}$ pena, (ni) gloria, descanso ni tormento! A

Triste vida es tener el sentimiento $\mathbf{A}$ Tal, que huye sentir lo que desea; $\mathbf{C}$ Su pensamiento a otros lisonjea, $\mathbf{C}$ Yo enemigo de mí siempre lo siento. A

\footnotetext{
${ }^{87}$ I. López de Mendoza, op. cit., p. 156-157.
} 
Con chismerías de enojo y de cuidado $\mathbf{D}$ Me viene, que es peor que cuanto peno, $\mathbf{E}$ $\mathrm{Y}$, si algún placer me trae, con él me va. $\mathbf{F}$

Como a madre con hijo regalado $\mathbf{D}$ Qué si llorando (le) pide algún veneno, E Tan ciega está de amor, que se lo da. F

(Soneto XL Diego Hurtado de Mendoza)

En los siguientes sonetos el marqués de Santillana y Diego Hurtado de Mendoza vuelven a reproducir un esquema de rimas con tres consonancias en los cuartetos, aunque con diferente disposición de las rimas en el segundo cuarteto: ABAB BCCB DEF DEF (Marqués de Santillana) y ABAB BCBC DEF DEF (Diego Hurtado de Mendoza). Ambos esquemas de rimas son tan insólitos que es lógico suponer que el de Hurtado de Mendoza está inspirado en el del Marqués de Santillana.

\section{Soneto XXX}

Venció Aníbal al conflicto de Canas A e non dubdava Lierio, si quiera, $\mathbf{B}$ q'en pocos días o pocas semanas $\mathbf{A}$ a Roma con Italia poseyera. B

Por cierto al universo la manera $\mathbf{B}$ plugo, e se goza en grand cantidad $\mathbf{C}$ de vuestra tan bien fecha libertad $\mathbf{C}$ onde la Astrea dominar espera. B

La Gracïa leemos sea dada D a muchos, e a pocos la perseverança, $\mathbf{E}$ pues de los raros sed vos, Rey prudente; $\mathbf{F}$

E non vos canse tan vil jornada, D mas conseguidla toliendo tardança $\mathbf{E}$ quanto es loable, bueno e diligente. $\mathbf{F}$

(Soneto XXX ${ }^{88}$ Marqués de Santillana)

\section{Soneto XXXVII}

Tiempo vi yo que Amor puso un deseo A honesto en un honesto corazón; B

${ }^{88}$ I. López de Mendoza, op. cit., p. 173. 
tiempo vi yo, que ahora no lo veo, $\mathbf{A}$ que era gloria y no pena mi pasión; $\mathbf{B}$

tiempo vi yo que por una ocasión $\mathbf{B}$ diera angustia y congoja y, si venía, $\mathbf{C}$ señora, en tu presencia, la razón $\mathbf{B}$ me faltaba y mi lengua enmudecía. C

Más que quisiera he visto, pues amor $\mathbf{D}$ quiere que llore el bien y sufra el daño $\mathrm{E}$ más por razón que no por acidente. $\mathbf{D}$

Crece mi mal y crece en lo peor, $\mathbf{D}$ en arrepentimiento y desengaño, $\mathbf{E}$ pena del bien pasado y mal presente. $\mathbf{F}$

(Soneto XXXVII de Diego Hurtado de Mendoza)

Ahora bien, comparado con los poetas de su generación, Mendoza experimenta con más combinaciones de rimas, además de combinarlas de formas diferente a ellos, y con independencia de que el tema tratado sea amoroso, satírico o burlesco. En cambio, en Garcilaso y Cetina predomina el paradigma ABBA ABBA CDE CDE. Sin embargo, en Boscán y Acuña se produce una mayor variedad en los tercetos, que pueden ser de sólo dos rimas en la combinación CDC DCD más abundantes.

Tal y como hemos visto, ante la relativa uniformidad en las combinaciones de las rimas de Garcilaso, Boscán, Cetina y Acuña; lo primero que llama la atención en Mendoza es que él emplea siete combinaciones diferentes en los cuartetos y ocho combinaciones de rimas en sus tercetos. El número de variaciones es tan grande con respecto a su grupo generacional que nos hace pensar que tanta variación supone un juego una es una forma de experimentación con una nueva estrofa, hasta entonces desconocida.

\section{Final.}

He pretendido estudiar el proceso de adaptación al metro italiano de un poeta formado en el arte de cancionero y, al mismo tiempo, tratar de delimitar las corrientes que influyeron y confluyeron en sus sonetos.

Este trabajo ha consistido fundamentalmente en un exhaustivo análisis métrico de los sonetos de Diego Hurtado de Mendoza; análisis en el que 
hemos evaluado y explicado esas influencias que inciden decisivamente en el proceso de adaptación al endecasílabo.

Se ha comprobado que, aún siendo Hurtado de Mendoza perteneciente a la misma época, viviendo las mismas circunstancias y recibiendo la misma formación poética que sus compañeros de generación, existen rasgos en sus endecasílabos que lo acercan más a la lírica de cancionero y que lo desvinculan del proceso de adaptación emprendido por el resto de poetas del XVI.

Como consecuencia de todo esto, se ha demostrado la necesidad de analizar los sonetos de Mendoza desde dos posibles enfoques o influencias: tradición y novedad. Para ello, hemos considerado la influencia ejercida por los rasgos característicos del arte mayor y menor castellano.

Desde el primer momento, existe en los sonetos de Hurtado de Mendoza la voluntad de asimilarse al nuevo metro, aunque, como ya hemos visto, esa práctica del endecasílabo se ve dificultada por hábitos procedentes de la lírica anterior de cancionero. Los resultados obtenidos del análisis métrico confirman esa tendencia principal en el estilo poético de Diego Hurtado de Mendoza, todavía lastrado por antiguas resonancias de la lírica cancioneril.

Después de todo lo visto, parece posible poder sostener que existe una vinculación clara entre los sonetos de Mendoza y el arte de cancionero, pues encontramos en sus versos un rasgo característico del cancionero: el verso agudo. Consecuentemente, todo lo analizado parece indicar que las divergencias observadas entre Mendoza y los poetas de su generación, con respecto al uso del verso agudo, estriban, en mayor medida, en cuestiones ideológicas que muestran que en Mendoza no existe una verdadera ruptura con las formas métricas heredadas del arte cancioneril.

En el estilo de Mendoza también queda alguna otra huella característica del conceptismo del XV, presente sobre todo en "los juegos de palabras" empleados por Mendoza para intensificar la rima. Esa reiteración y juegos de palabras se muestran, como ya hemos estudiado, en una especie de rima interna y es otro rasgo claro de influencia cancioneril.

Por otra parte, debemos destacar que el influjo del Marqués de Santillana fue también de importancia decisiva en los endecasílabos de Hurtado de Mendoza. No quiero decir con esto que toda la poesía de Mendoza esté influenciada por Santillana, ni que reproduzca todos los rasgos de forma de sus endecasílabos, pero sí que, en la utilización del ritmo dactílico o en el uso de paradigmas de rimas insólitos para el resto de poetas del XVI, se observa 
cierta afinidad entre ambos que nos hace pensar en que en ciertos momentos la poesía de Mendoza se viese influenciada por la del Marqués de Santillana.

El estudio advierte, también, cierta proximidad entre los recursos empleados por Diego Hurtado de Mendoza y los utilizados por los primeros sonetistas del duecento italiano, concretamente en la tendencia a romper el orden de las rimas, prefiriendo las rimas cruzadas $\mathrm{ABAB} A B A B$ como era frecuente, según ya hemos visto, en esos primeros sonetistas italianos $y$, también, en el Marqués de Santillana. Por consiguiente, podemos concluir que, junto a estas transformaciones de la poesía italianizante de Hurtado de Mendoza mantuvo importantes elementos de continuidad con el panorama poético anterior.

También hemos podido comprobar que, sin olvidar las antiguas resonancias del ritmo del arte cancioneril, Mendoza profundiza, con mayor o peor acierto, en el ritmo del endecasílabo. Sin embargo, debemos destacar que el ritmo dactílico, de sus endecasílabos, junto con otras peculiaridades rítmicas como es la acentuación en $5 .^{a}, 7$. $^{\mathrm{a}}$ y 8 . $^{\mathrm{a}}$ suponen un punto de inflexión con los poetas de su generación, dado que estos poetas de principios del XVI (coetáneos de Mendoza) rechazaban los endecasílabos con ritmo dactílico por ser ritmos del verso de arte mayor que sonaban a viejo. Sin duda, un rastro claro de la herencia del arte cancioneril observable en sus endecasílabos.

En líneas generales, todos los poetas de principios del XVI mantuvieron cierto equilibrio entre tradición medieval y las nuevas corrientes métricas llegadas de Italia, aunque siempre orientando su poesía hacia la estética y mesura del verso, donde ritmo estaba asociado emotividad que pretendían transmitir. Sin embargo, Mendoza se queda al margen de ese proceso iniciado por sus compañeros.

Estas son en resumen, las principales características del endecasílabo empleado por Hurtado de Mendoza en sus sonetos: por una parte, hace un uso muy destacado del verso agudo, uso que le lleva a establecer grandes diferencias formales con los restantes poetas de su generación, más partidarios, estos últimos, de desligarse por completo de ese resto del verso octosílabo; por otra parte, su utilización de licencias métricas, algunas de ellas de uso muy cuestionable, y que en último caso evidencian una poesía descuidada y lastrada por antiguas resonancias de la lírica del XV.

No obstante, hay que destacar el papel innovador de las rimas de Hurtado de Mendoza, ya que en ellas es mucho más dado a la innovación, 
al juego, a la experimentación. Probablemente, porque consideraba el soneto como un campo experimental para extravagancias y juegos, para rimar palabras equívocas, para realizar rimas internas, o para intentar esquemas de rimas complicados.

Finalmente, hay que destacar que todas esas circunstancias que vinculaban sus endecasílabos con antiguas resonancias dela lírica decancionero limitaron su nueva labor creadora en endecasílabos, ya que son rasgos que subsisten a lo largo de las décadas sin que aparezca la menor intención de abandonar esas costumbres que comenzaban a considerarse como arcaísmos. Por tanto, este estudio muestra a un poeta en posesión de los recursos técnicos para la composición en endecasílabos, pero que, sin embargo, muestra cierta rudeza técnica que subraya el papel precursor y transitorio de sus sonetos dentro de la gran poesía del siglo XVI. 


\section{BibLIOGRAFÍA}

Alonso, D., Poesía Española, Madrid, Gredos, 1971.

------,«Elogio del Endecasílabo», Obras Completas II, Madrid, Gredos, 1973, pp. 539-542.

AlONSO SCHÖKEL, L., Estética del ritmo poético, Madrid, Gredos, 1970.

BAEHR, R., Manual de versificación española, Madrid, Gredos, 1975.

Balbín LucAs, R., Sistema de la rítmica castellana, Madrid, Gredos, 1975.

BLECUA, A., «La epístola al lector a la edición de las obras de Hurtado de Mendoza (Madrid, 1610): ¿un viejo nuevo texto cervantino?», en Ínsula, (Abril - Mayo 2005), pp. 2-6.

Blecua, J. M., (ed.) Poesía de la Edad de Oro I Renacimiento, Madrid, Clásicos Castalia, 1991.

«Corrientes poéticas en el Siglo XVI»,Sobre poesía de la Edad de Oro, 1970, pp. 11-24.

Boscán, J., Obra Completa, ed. Carlos Clavería, Madrid, Cátedra, 1999.

Bousoño, C., Teoría de la expresión poética, Madrid, Gredos, 1976.

CAnellada, M. ${ }^{\mathrm{a}}$ J., Pronunciación del español. Lengua hablada y lengua literaria, Madrid, Castalia, 1987

Cueva, J., Exemplar poético II, edición crítica de José María Reyes Cano, Sevilla, Alfar, 1986, p. 186.

Diccionario de la lengua española, Madrid, Real Academia Española, 1994, 2 vols.

Domínguez CAPARrós, J., Diccionario de Métrica española, Madrid, Paraninfo, 1992. -, Métrica española, Madrid, Síntesis, 1993.

FubINI, M., «El soneto», Métrica y poesía, Barcelona, Planeta, 1970.

FuCILLA, J.G., «two generations of petrarchism and patrarchists in Spain»en Modern philology, Chicago, (1930), T. XXVII, pp. 277-295.

Gallego Morell, A., «Escuela de Garcilaso», Renacimiento español, Universidad de Granada, Comares S. L, 2003.

Garcilaso De La Vega, Poesías completas castellanas, ed. de Elías Rivers, Madrid, Clásicos Castalia, 1996.

González Cuenca, J., (ed.) Cancionero general; recopilación de Hernando del Castillo, Madrid, Castalia, 2004.

Hurtado De Mendoza, D., Poesía Completa, ed., José Ignacio Díez Fernández, Barcelona, Planeta, 1989.

Hurtado De Mendoza, D., Poesías, ed. de Luis F. Díaz Larios y Olga Gete Carpio, Madrid, Cátedra, 1990.

JAKOBSON, R., Ensayos de lingüística general, Barcelona, Seix Barral, 1981.

Jauralde Pou, P., Varela Merino, E. y moíño sánchez, P., Manual de métrica española, Madrid, Castalia Universidad, 2005.

LAPESA, R., Garcilaso, Estudios completos, Madrid, ISTMO, 1985.

---------, La obra literaria del Marqués de Santillana, Madrid, Ínsula, 1957.

LÁzAro CARreter, F., «Rimas categoriales y acategoriales», De poética y Poéticas, Madrid, Cátedra, 1977, 1990, pp. 200-206. 
Estudios de poética, Madrid, Taurus, 1976.

Marqués De Santillana, Poesías completas, ed. Maxim P.A.M Kerkhof y Ángel Gómez Moreno, Madrid, Clásicos Castalia, 2003.

Menéndez Pidal, R., Historia de la lengua española, Fundación Ramón Menéndez Pidal, Madrid, Real Academia, 2005.

Montero Reguera, J., «En torno a un soneto garcilasiano de Lope de Vega» en Actas del XIII Congreso de la Asociación Internacional de Hispanistas, Madrid 1998.

Madrid, Castalia, 2000, Vol. I, pp. 616-622.

Navarro Tomás, Manual de pronunciación del español, Madrid, C.S.I.C. -, Métrica española, Barcelona, Labor, 1995.

Ortografía de lengua española, Madrid, Real Academia Española, 1999.

PRIETO, A., La poesía española del siglo XVI, Madrid, Cátedra, 1984.

Quilis, A., Métrica Española, Barcelona, Ariel, 1984.

Rico, Francisco, «El destierro del verso agudo», Estudios de literatura y otras cosas, Barcelona, Destino, 2002, pp. 215-250.

Whinnom K., «Hacia la interpretación y apreciación de las canciones del Cancionero General de 1511», Filología XIII, (1968-1969), pp. 361-381.

Zamora Vicente, Alonso, Sobre Petrarquismo, Santiago de Compostela, Universidad de Santiago de Compostela, 1948. 